\title{
The Effect of Lactobacillus brevis on Apoptosis and casp (casp8, casp3) Gene Expression in Hela Cancer Cells
}

\author{
Neda Chobdar ${ }^{1}$, Changiz Ahmadizadeh ${ }^{1 *}$
}

1. Department of Microbiology, Ahar Branch, Islamic Azad University, Ahar, Iran

Background: Cervical and breast cancer are considered to be the most common cause of death among Iranian women. Various studies have shown that probiotics are effective fighting cancer. The aim of the present study was to investigate the effect of Lactobacillus brevis on apoptosis and casp (casp3, casp8) gene expression in HeLa cancer cells.

Materials \& Methods: In this study, L. brevis bacteria were collected from the vaginal fluid of females referred to Alzahra Hospital and isolated and cultured in MRS agar medium. Inhibition of HeLa cancer cell proliferation by bacteria was evaluated by MTT assay. Apoptosis of cancer cells was measured by fluorescent microscopy using DAPI method. Finally, expression of Caspase and akt genes was measured by Real time PCR.

Results: The results indicated that $L$. brevis had the same effect on HeLa cancer cells $(P=0.42, P=0.26)$. On the other hand, there was no significant increase in akt gene expression ( $p>0.05)$.

Conclusion: Lactobacillus brevis bacteria can be considered biologically safe for the development of a novel, high-impact, low-throughput therapeutic strategy. On the other hand, side-by-side treatment and prevention against cancer will be costeffective.

Keywords: Lactobacillus brevis, Caspase, Cancer, HeLa cells

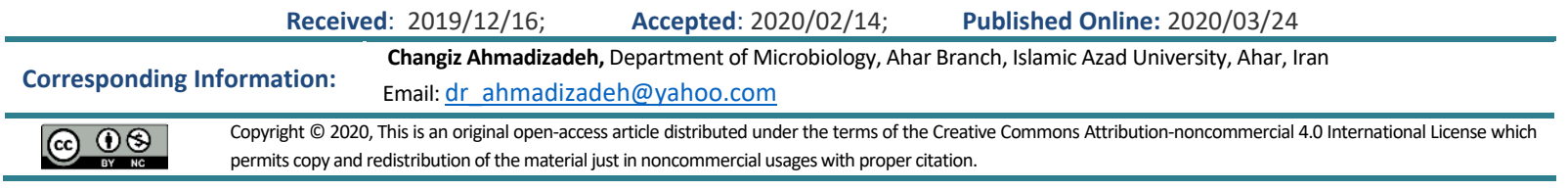

Use your device to scan and read the article online

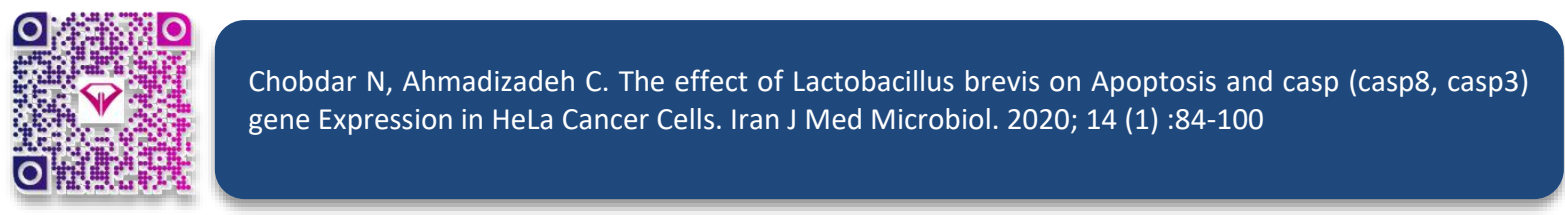

Download citation: BibTeX | RIS | EndNote | Medlars | ProCite | Reference Manager | RefWorks

Send citation to: $\otimes_{\text {Mendeley }} \mathbf{z}$ zotero $\underline{\Theta}$ RefWorks

\section{Introduction}

The most common malignancy of cancer in women is cervical cancer, which is the third most common cancer of the genital tract after breast cancer (1). HeLa is a type of immortalized cell line used in scientific research as the oldest and most common category (3). This cancer is caused by the irregular growth of the cervical epithelial cells and the continuous loss of cells worldwide. The most important factor is Human papillomavirus (HPV). For cancer research studies, HeLa cancer cells are used, the advantages of which include the ability to proliferate indefinitely and endure long passages (5). Various studies have shown that probiotics have an effective role in the fight against cancer. Their anticancer mechanisms include suppressing mutations, inhibiting cancer-causing compounds and tumors, and strengthening the immune system. In 6\% of cases, HPV infection is the major factor that can be prevented using probiotics (6). The anticancer effects of probiotics are by preventing the conversion of procarcinogen to carcinogen, binding and inactivating mitogenic compounds, reducing the growth of pro-carcinogenic 
bacteria, reducing mitogen uptake and enhancing immune function (7). One of the functional mechanisms of probiotics, including Lactobacillus, is the induction of anti-cancer apoptosis (8). Apoptosis, which occurs in response to various stressors such as physiological, pathological or cytological stimuli in the body (9), plays an effective role in controlling the physiology of the body and many pathological conditions. Resistance to apoptosis is one of the hallmarks of cancer and reduced susceptibility to apoptosis results in increased threshold therapy for classic cases such as chemotherapy and radiotherapy (10).

Most anticancer drugs induce apoptosis through the mitochondrial pathway (12). Caspases are proteases that act as essential initiators and performers of the apoptotic process. Classically, the caspase 3 cascade is most likely initiated by autoproteolysis by breaking the so-called initiator caspases $(2,8,9,10,12)$. Initial caspases break down and activate caspases (caspases 3,6 , and 7). This results in an apoptotic process (13).

Importance of Caspase-9 is that it is upstream signaling of Caspase 3 and is stimulated by 1-Apaf / cytochrome $\mathrm{c}$ and is inhibited by the oncogene product Akt (16). Two major pathways for apoptosis have been identified:

1: responds to foreign pathway (death receptor dependent pathway) and internal factors such as DNA damage;

2: Internal pathway (mitochondrial pathway). The external pathway of apoptosis begins through death receptors and leads to activation of caspase 8 . Activated caspase 8 can directly activate executable caspases, and activated caspases such as caspase 3 are subsequently activated by the initiator caspases and trigger the caspase cascade. (17). The aim of this study was to investigate the effect of Lactobacillus brevis on apoptosis and casp8 (casp8, casp3) gene expression in HeLa cancer cells.

\section{Methods and Materials}

In this cross-sectional study, sampling of vagina was performed on women referring to Alzahra Maternity Hospital (Tehran, Iran) from ..... to ..... Eight out of 70 samples were positive for $L$. brevis bacteria which were isolated after MRS agar culture. To maintain the samples at $-70^{\circ} \mathrm{C}$, a new 12 -hour culture of $L$. brevis was prepared in MRS agar culture medium. Then a standard bacterial loop was removed and $25 \%$ glycerol was added to MRS broth. After $12 \mathrm{~h}$ incubation, the samples were gradually cooled and placed in $-70^{\circ} \mathrm{C}$ freezer.
Bacterial identification in the collected samples began with DNA extraction. DNA was extracted by agarose gel electrophoresis and spectrophotometric methods. PCR was performed on DNA. The primers sequence was designed by oligo5 software for PCR (Table 1).

In this project, HeLa cancer cells were obtained from Pasteur Institute of Iran's Cell Bank. Cells were cultured in flasks containing $5 \mathrm{~mL}$ RPMI1640 medium supplemented with $10 \%$ Fetal Bovine Serum (FBS), antibiotic penicillin $0.1 \mu \mathrm{g} / \mu \mathrm{L}$ and streptomycin 0.1 $\mu \mathrm{g} / \mu \mathrm{L}$.

To determine the viability test, cells were stained with trypan blue. Cell counting was performed. The mean was multiplied by 104 and dilution coefficient and the number of cells was obtained in one milliliter of solution.

Microculture Tetrazolium Test (MTT) and Dapi staining was done. Then the RNA was extracted. Samples were randomly electrophoresed on agarose gel to evaluate the quality of the extracted RNAs. For this purpose, $2 \%$ gel was made and then the samples were electrophoresed at $80 \mathrm{~V}$ for 1 hour.

RNA was extracted from cDNA to measure gene expression changes by real-time PCR. The primers used were designed by oligo 5 software and then blasted by the NCBI (http://www. ncbi. nlm. nih. gov).

The collected data were analyzed using SPSS 19 (SPSS Inc., Chicago, IL., USA).

\section{Results}

The aim of this study was to investigate the mechanism of $L$. brevis as probiotic inhibitory effect on HeLa cervical cancer cells and its effect on expression of casp8, casp3 and $a k 1$ genes. The results of the relevant tests were as follows:

\section{Toxicity of Isolated Bacteria on HeLa Cancer Cell}

In order to evaluate the toxicity of Lactobacilli bacteria on HeLa cells, the number of cells needed for the experiment were optimized first, and then cultured in 10,000 wells per 96 well plate. When the number of cells was doubled, the bacteria were cultured with increasing concentrations and then treated for 24,48 and 72 hours. After $4 \mathrm{~h}$ no effect was observed but in the $12 \mathrm{~h}$ of treatment, lactobacillus bacteria were observed. During 48 hours of incubation, results were greater than IC50. The results of MTT are shown in Figure 1. 
Table 1. Sequences of primers used to identify Lactobacillus brevis bacteria

\begin{tabular}{|c|c|c|}
\hline Gene & $\left(5^{\prime}-3^{\prime}\right)$ & Product size \\
\hline \multirow{2}{*}{ 16s rRNA } & F: GAACGCGAAGAACCTTAC & \multirow{2}{*}{1500 bp } \\
\hline & R: GCGTGTGTACAAGACCC & \\
\hline
\end{tabular}

Table 2. Characteristics of primers used

\begin{tabular}{|c|c|c|}
\hline $\begin{array}{l}\text { Primer's } \\
\text { name }\end{array}$ & & Primer Sequence \\
\hline \multirow{2}{*}{ CASP3 } & Forward & 5-TACCCTGAAATG GGCTTGTGT -3' \\
\hline & Reverse & 5-' GTTAACACGAGTGAGGATGTG - 3' \\
\hline \multirow{2}{*}{$A K T 1$} & Forward & 5'-TGCCCACACGCTTACTGAGA-3' \\
\hline & Reverse & 5'-CAAGTAGTCCAGGGCGGACA-3' \\
\hline \multirow{2}{*}{ Casp8 } & Forward & 5' - CCCAAGAGGAACAGCGATAAG -3' \\
\hline & Reverse & 5'- GGTCGATGGTGGTGTCAAAG -3' \\
\hline \multirow{2}{*}{ GAPDH } & Forward & 5 -CGGTGGATCCCCTTTATTG-3 \\
\hline & Revers & 5-CTAACCAGGAATTCCGATG-3 \\
\hline
\end{tabular}

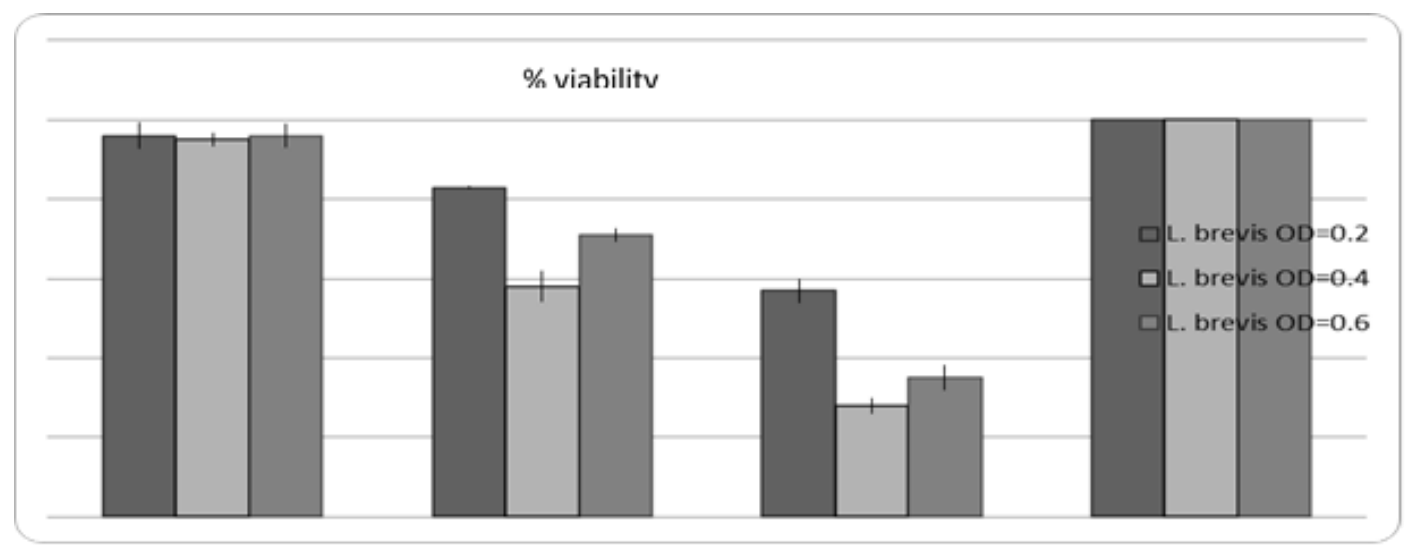

Figure 1. The effect of different time treatments on Lactobacillus brevis Culture.
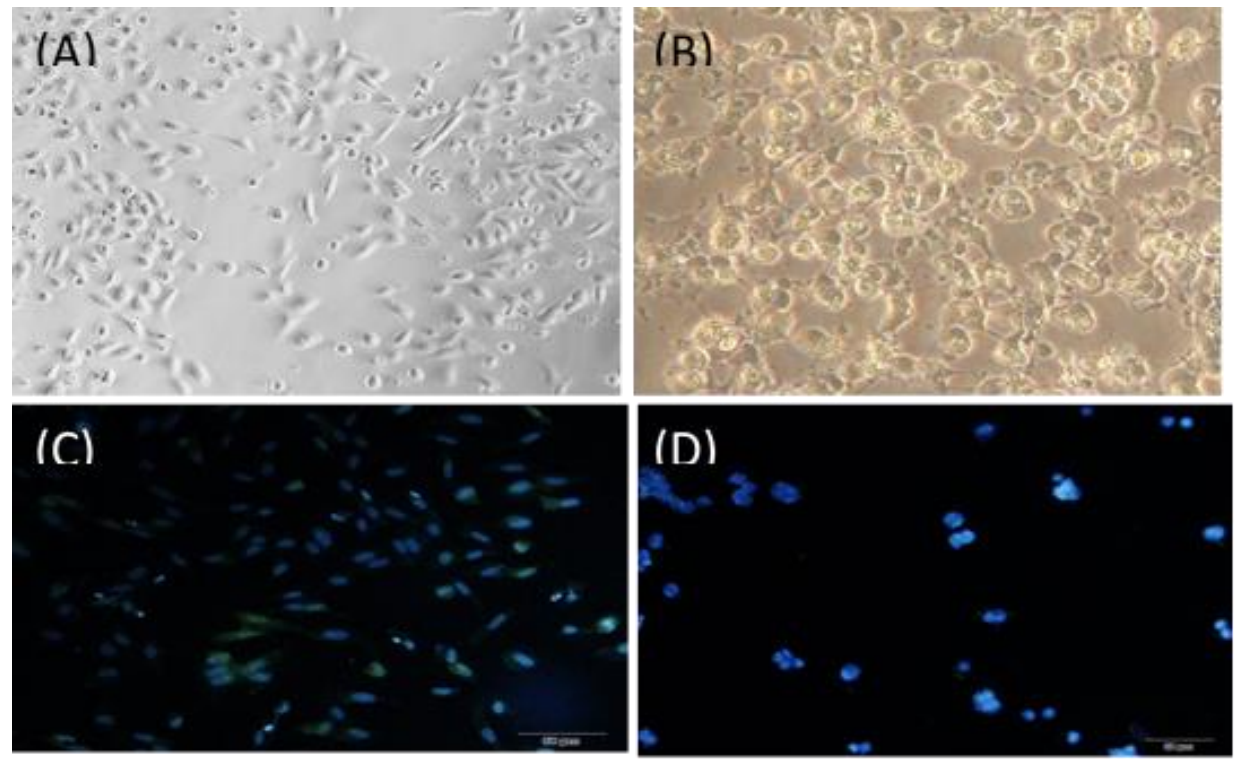

Figure 2. Staining of cells treated with DAPI staining 


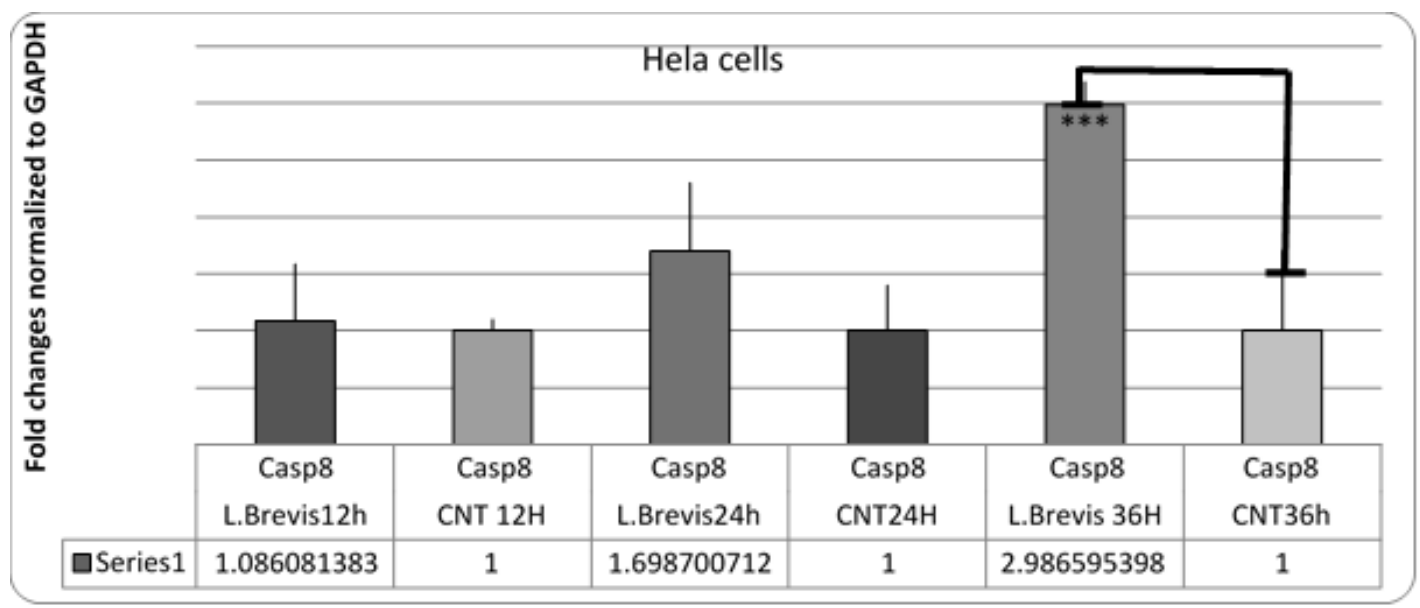

Figure 3. Diagram of changes in Casp8 gene expression in HeLa cells affected by L. brevis.

$$
* * * ;(P=0.42)
$$

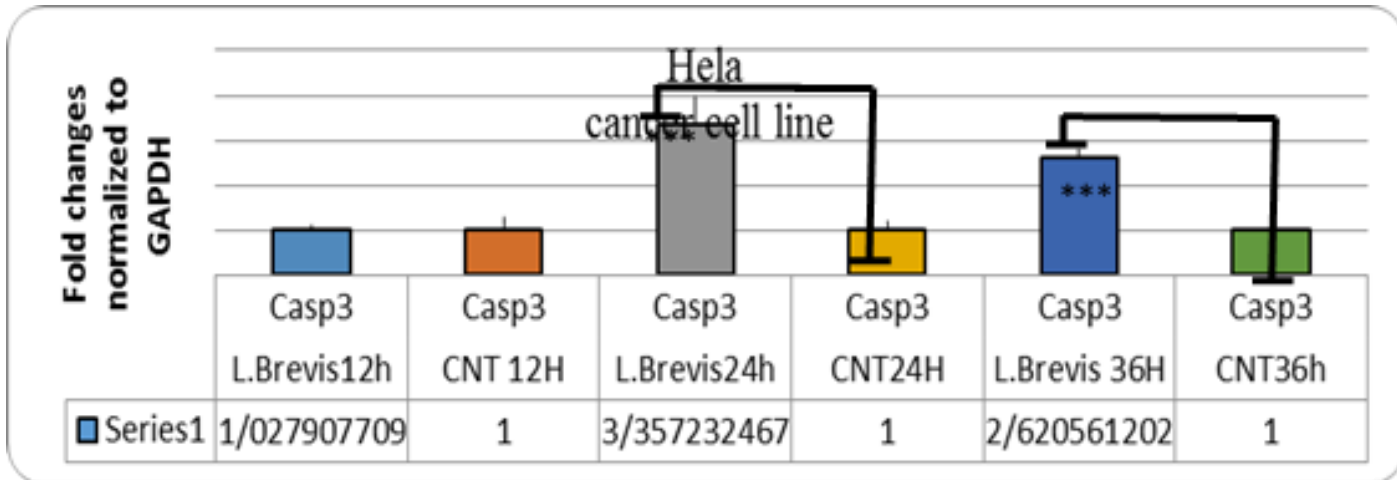

Figure 4. Graph of expression of CASP3 gene in HELA cells affected by L. brevis.

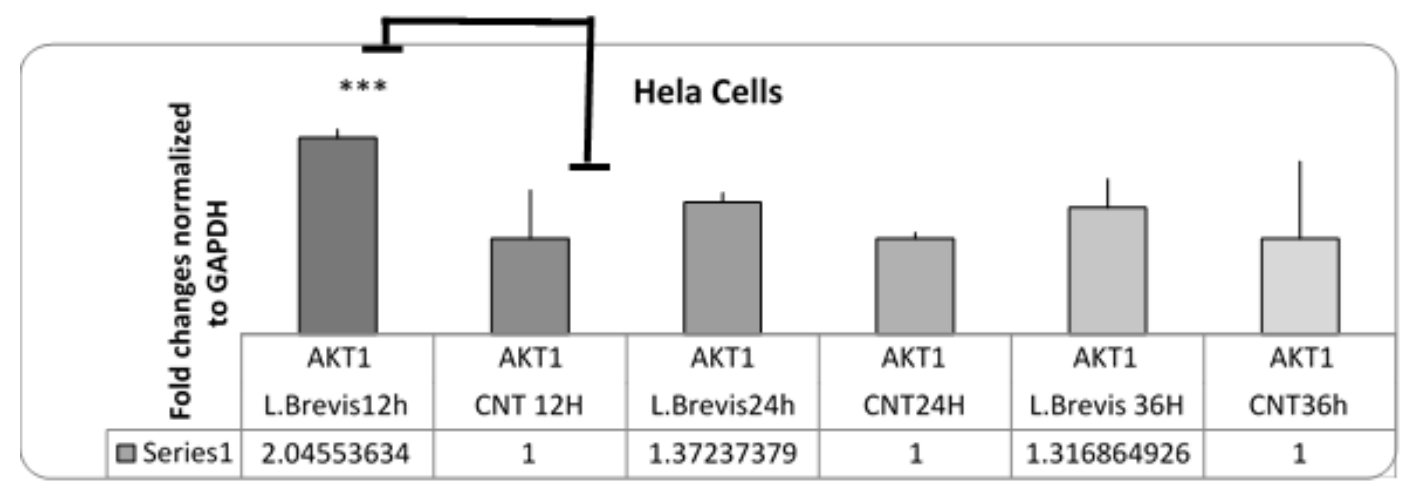

Figure 5. Chart of changes in akt1 gene expression in HeLa cells affected by L. brevis $(P=0.42)$. The akt1 gene had increased expression in the early hours due to the resistance of the cancer to apoptosis.

\section{DAPI staining}

The results of DAPI staining to evaluate apoptosis from different treatments are as follows (Figure 2). Treated cells compared to non-treated cells (with killed bacteria) entered apoptosis and smaller nuclei have formed.

To evaluate gene expression changes, HeLa cells were affected by IC50 concentration of lactobacillus bacteria obtained in MTT assay. RNA was then extracted from these cells.

HELA cells were treated with IC50 concentrations of lactobacillus isolates for 12, 24 and 36 hours, respectively. P-value $<0.05$ was considered significant.

In addition, in order to ensure the apoptosis of the cells upstream of the caspase 3 gene, caspase 3 was also investigated. There was a significant increase in this gene. The akt1 gene had increased expression in 
the early hours due to the resistance of the cancer to apoptosis.

Since akt1 gene plays an important role in the biology of cervical cancer, it has also been evaluated with regard to its anti-apoptotic effect to make it more reliable. As shown in the Figure 5, the akt gene did not increase significantly at 24 and $36 \mathrm{~h}$, and the cells would be allowed to initiate apoptosis.

\section{Discussion}

he main feature of cancer cells is uncontrolled cell proliferation. It also provides resistance to programmed death, so a factor that induces apoptosis in cancer cells can be recognized as an anticancer drug (20). There are also foods that can have a positive impact on the control of cancer cell growth. Therefore, dietary compounds and their role in human health have attracted the attention of many scientists.

Probiotics are some of the non-pathogenic organisms in the food that are present in the digestive system. These microorganisms also have beneficial effects on the health of the host. Certain probiotics have been reported to have anticancer activities (21). The results of tests on HeLa cell line and examination of genes involved in apoptosis of these cells showed that Lactobacillus brevis has the ability to inhibit the growth of HeLa cancer cells. Extract of this bacterium increased casp8 and casp8 gene expression at $24 \mathrm{~h}$ and $36 \mathrm{~h}(P>0.05)$. However, no significant increase in akt1 gene expression was observed. Since caspase gene is a pro-apoptotic protein, apoptosis of cells was predicted by treatment with bacterial extract. Also, apoptosis of cancer cells by treatment of these bacteria with DAPI staining showed the antibiotic effect of the isolated probiotic.

Various studies on probiotics have shown that probiotics are living microorganisms that have a positive effect on improving the pathogenicity of the host and balance the number of microorganisms in the gut and strengthen the immune system. Probiotics play an important role in improving health. In the absence of these bacteria, the balance of the intestinal flora becomes disrupted and disease and inflammation occur (22).

Research has also shown that vaginal lactobacilli are not only effective in preventing bacterial and fungal infections, but also in controlling and preventing viral and cancer infections. According to these results, enhancing and preserving the microbial flora of vaginal Lactobacillus is one of the most important and low cost methods of cancer prevention. Lactobacillus family bacteria are commonly found as probiotics in yogurt and other dairy products. The regulating and stimulating properties of these bacteria on the host immune system have been well documented in other studies (23).

The results of tests performed on HeLa cell line and cell treatments and the study of genes involved in apoptosis in this study showed that the expression of caspase gene that was changed after treatment with Lactobacillus extract Further studies have been done on this probiotic bacterium and its anticancer properties that have proven the nutritional value of this probiotic. Cancer cells divide through a series of regulated processes, and the remainder of their cells are absorbed by adjacent tissues and immune cells. Numerous studies have shown that probiotic bacteria can play an important role in regulating apoptosis through internal and external pathways that have potential mechanisms for cancer prevention. This is consistent with the present study (24).

Investigating the influence of Lactobacillus brevis on gastric gastritis healing caused by Helicobacter pylori mouse model Orcid et al., (2018) showed that inflammation and remission were reduced in groups infected with $L$. brevis infection. The eradication rate of H. pylori infection in the treatment group showed a decrease in inflammation after histological examination. The results of the Orcid et al. study are consistent with our study (25).

Recent studies have confirmed the presence of caspases and $A K T$ signaling pathway in cervical cancer cell and cancer cell death. As a result of this study, Akt1, a major mediator of the signaling pathway, which induces cancer cell survival, inhibits apoptosis of cancer cells, and drugs and therapies that inhibit $A K T$ signaling pathway induce apoptosis of cancer cells. This is also consistent with our study (27). Studies have shown that AKT is activated by a number of growth factors through the RAS, PI3 signaling pathway. AKT has been reported as a result of activation of cervical cancer. In high grade cervical cancers, gene is highly active. In another study, of the 44 cervical cancer samples, 33 reported active $A K T$. This finding suggests that activation of $A K T$ is a common process in cervical cancer. The $A K T$ pathway is an important target for the study of cervical cancer. The findings of this study are consistent with our study (28).

The issue that active form of caspase- 9 , cleaves procaspase 3 and induces caspase 3 activation may be important in apoptosis. In line with the importance of these two caspases in apoptosis, Sanguinarine increases caspase 3 and 9 treatment about 6 to 7-fold. In fact, these caspases are activated in human colon HT-29 cells, indicating that Sanguinarine induces apoptosis by a caspase-dependent pathway in this cell line (29). In a study in 2015, Jafari et al. it was reported that caspase 3 is a key regulator of apoptosis and is associated with the incidence of apoptosis in breast cancer. Therefore, it can be considered as an 
important marker for predicting response or resistance to therapeutic drugs (chemotherapy). The results of their study are consistent with our study (30). Concerning gastric cancer, it has also been reported that caspase 3 expression levels in gastric tissue of gastric cancer patients are lower than in normal gastric mucosa (31).

\section{Conclusion}

Lactobacillus brevis can be biologically safe for the development of a novel, high-impact, low side-effect therapeutic strategy. On the other hand, side-by-side treatment and prevention against cancer will be costeffective.

\section{Acknowledgement}

I would like to sincerely thank the Vice-Chancellor for Education and Research of the Islamic Azad University of Ahar Branch. I would like to thank all those who helped me during this research. It is worth noting that this article is the result of a thesis by Ms. Neda Chobdar at Islamic Azad University, Ahar branch, Iran.

\section{Conflict of Interest}

Authors declared no conflict of interests. 


$$
\begin{aligned}
& \text { مجله ميكروبشناسى يزشكى ايران } \\
& \text { سال If ـ شماره | - بهمن و اسفند 94 }
\end{aligned}
$$

\title{
تأثير لاكتوباسيل برويس برآيويتوز و بيان زنهاى كاسياز (casp3, casp8) درسلولهاى سرطانى HeLa
}

\author{
ندا جوبدار' ، جنكَيز احمدىزاده'"
}

'. كروه ميكروبيولوزى، واحد اهر، دانشكاه آزاد اسلامى، اهر، ايران

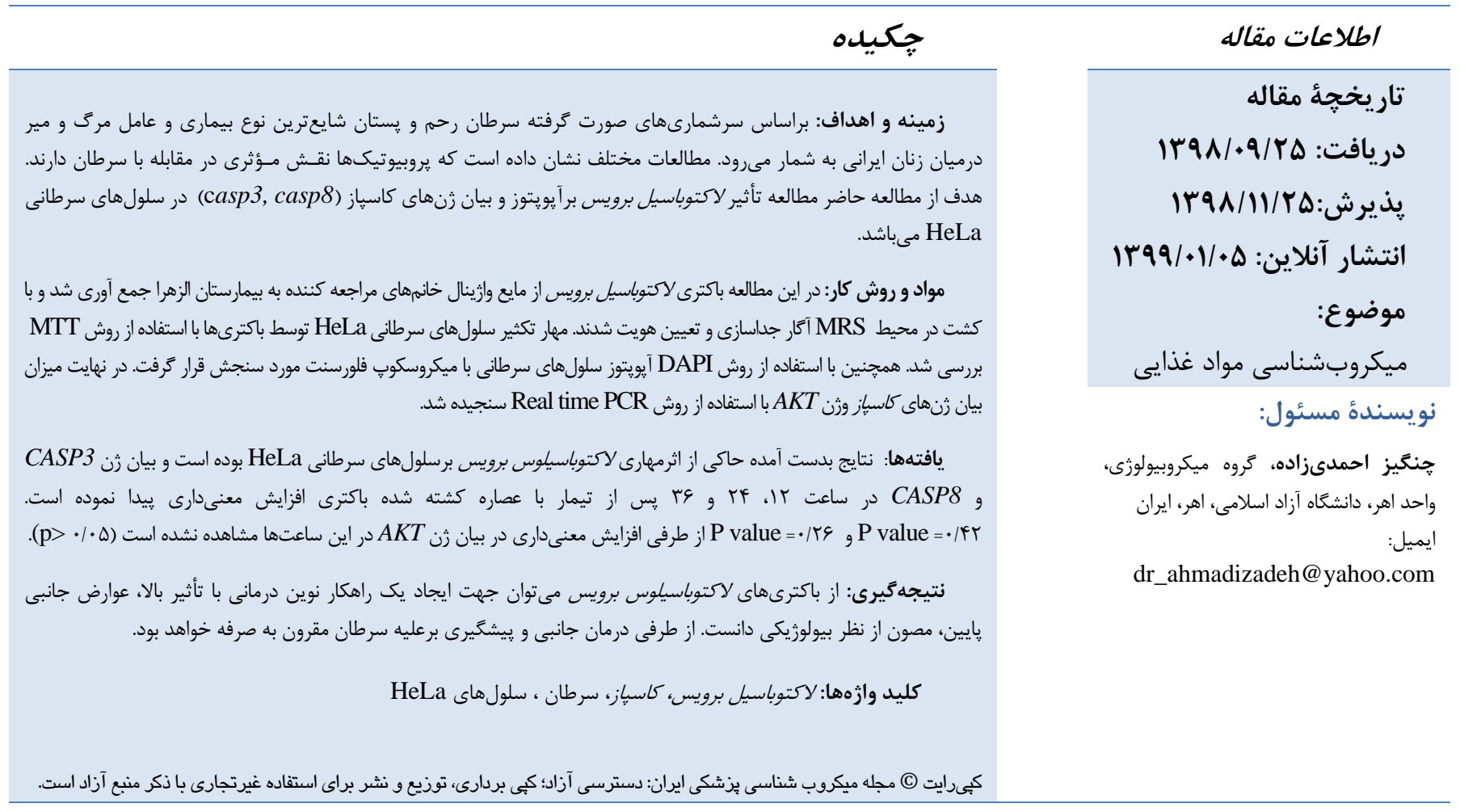

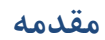

رeدa

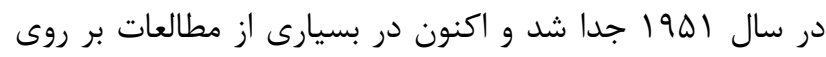

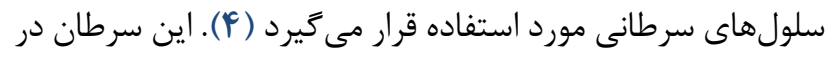

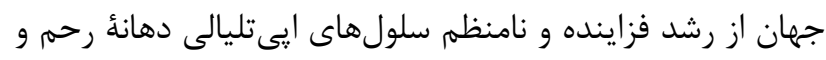

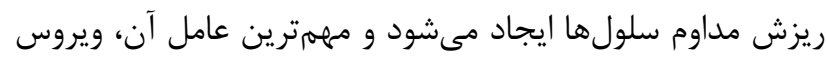

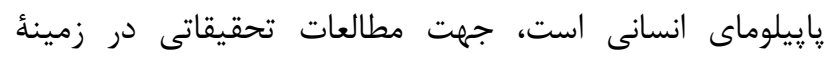

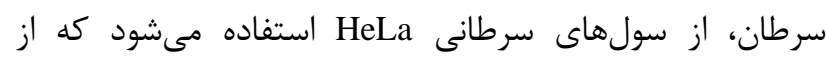

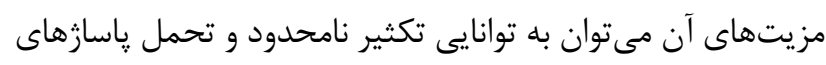

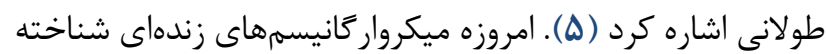

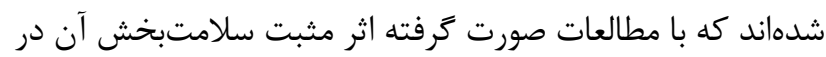

شايعترين بدخيمى سرطان در زنان، سرطان دهانه رحم إمان

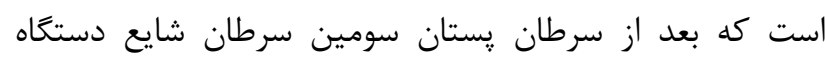

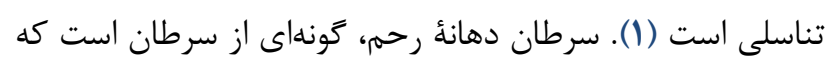

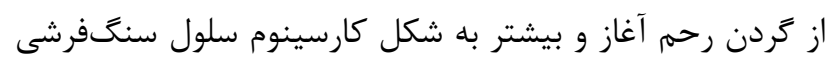

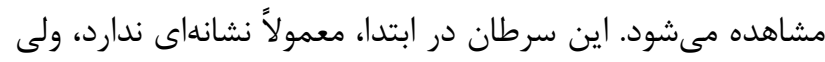

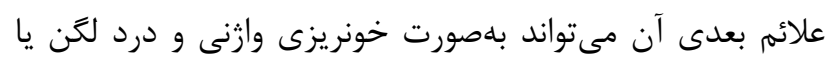

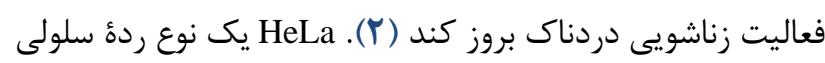

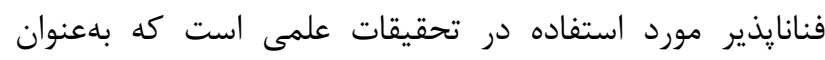

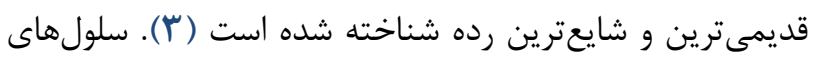

Majallah-i mīkrub/shināsī-i pizishkī-i Īrān. 
باقى مىماند. كاسياز -r فعالشده، مهار كننده DNase (فعال كننده

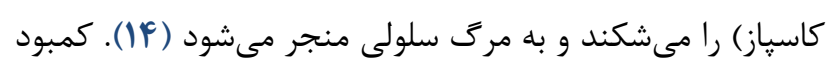

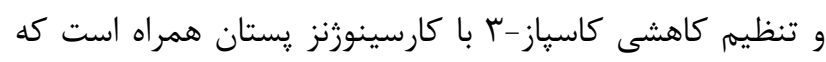

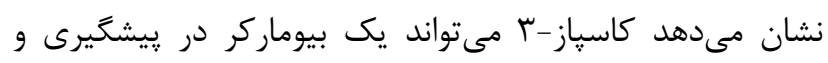

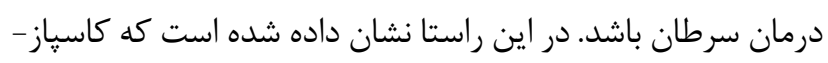

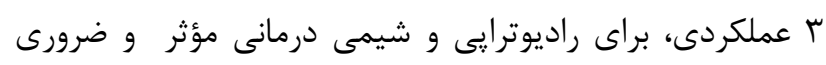

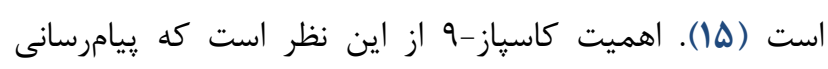

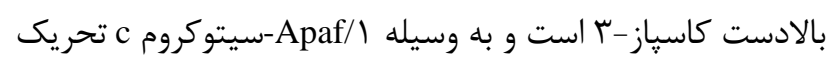

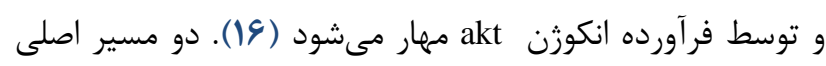
براى آيايتوز شناسايى شده است:

1:مسيرخارجى (مسير وابسته به كيرنده مرگ) و عوامل

$$
\text { داخلى از قبيل آسيب DNA إساسخ مى دهدي؛ }
$$

ז:مسير داخلى (مسير ميتو كندريايى). مسير خارجى آيويتوز

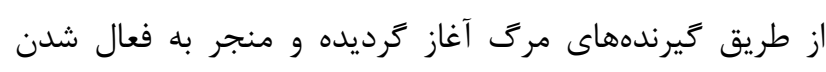

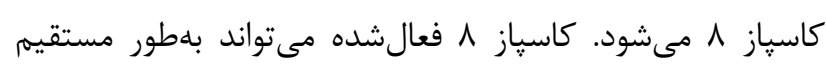

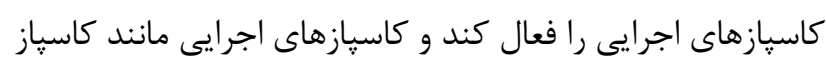

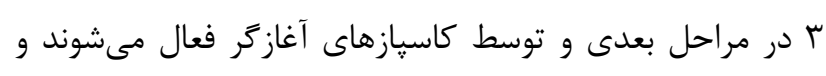

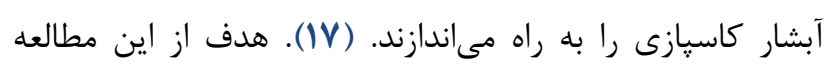

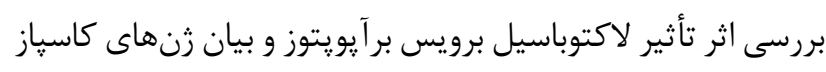
(casp3, casp8)

$$
\text { مواد و روشها }
$$

\section{نمونه تيرى و نكَّهدارى}

در اين مطالعه مقطعى، نمونه گيرى از وازن زنانى كه طى

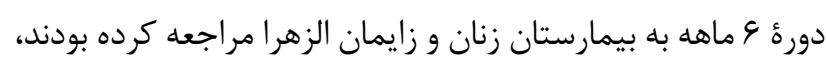

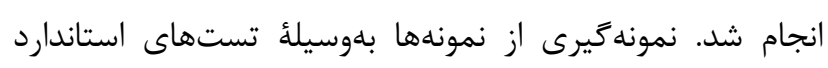

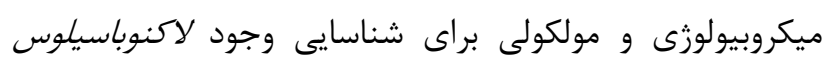

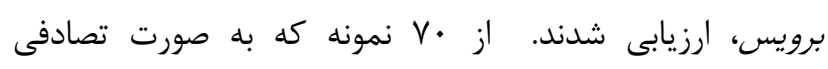

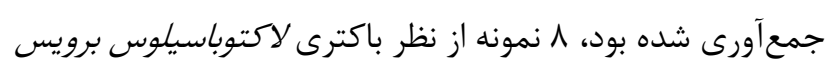

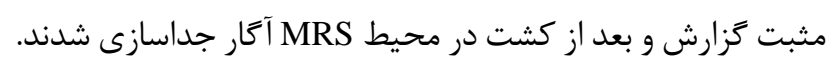

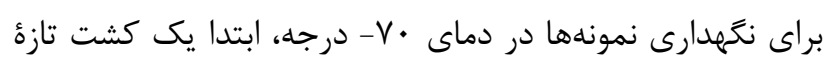

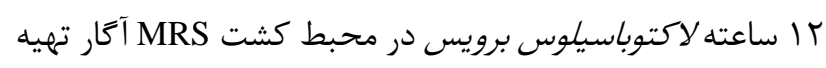

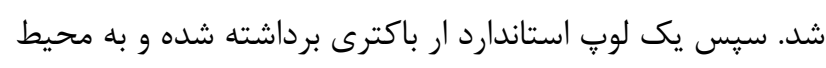

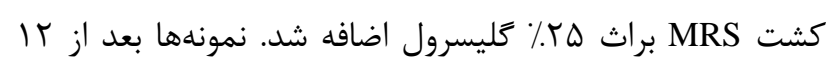

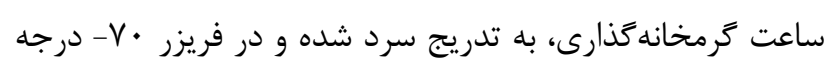
قرار گرفتند.
انسان به اثبات رسيده است. مطالعات مختلف نشان داده است كه

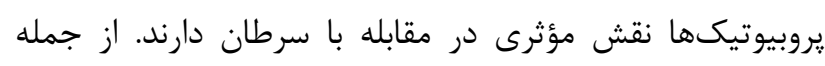

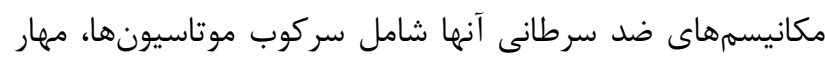

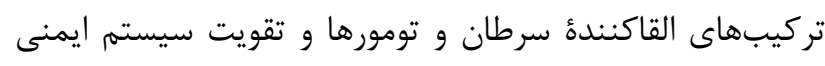

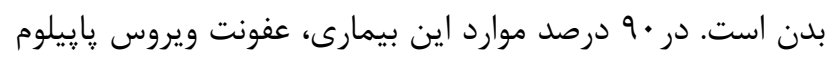

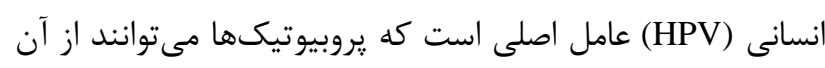

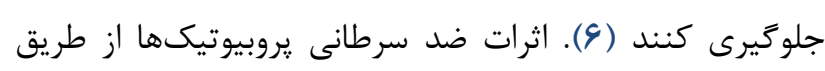

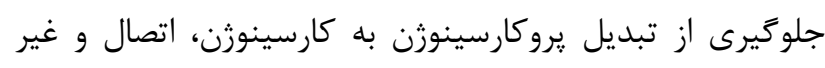

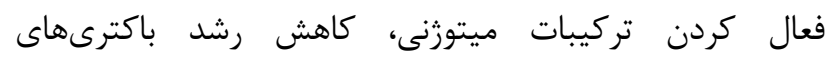

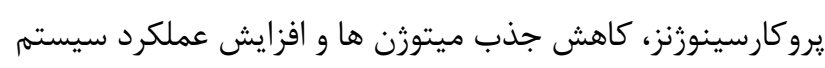

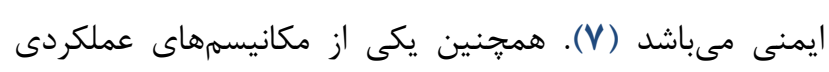

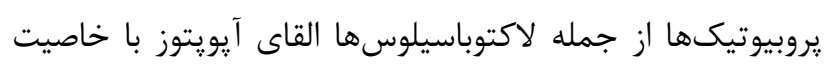

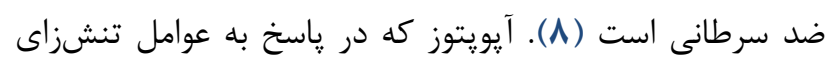

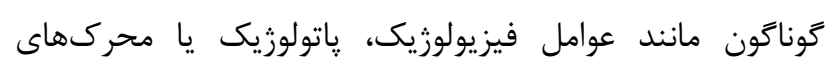
سيتولوزيك در بدن رخ مىدهد (9)؛ نقش موثرى در درون كنترل

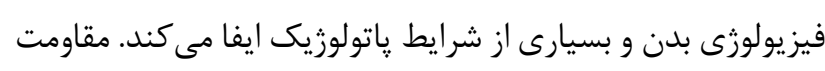

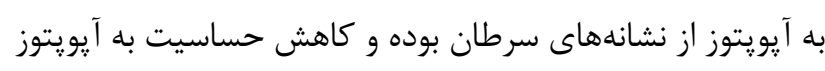

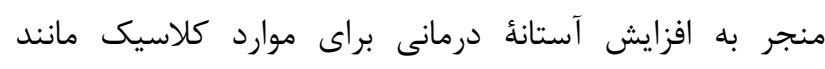
شيمىدرمانى و راديوترايى مىشود (•(1). يبتيدهاى كشفشده از موجودات دريايى موجب تحريك مرك سلولى با مكانيسمهاى مختلفى از جمله آيويتوز، تأثير بر تهري

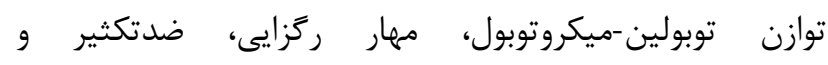

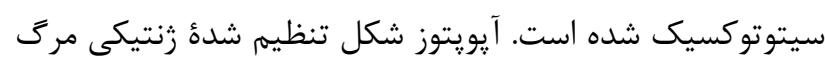
سلولى است كه نقش مهمى را در حذف كردن سلولهاى آلوندي آلوده،

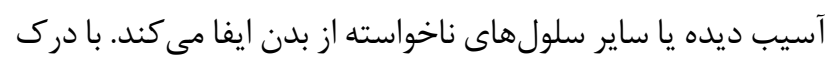

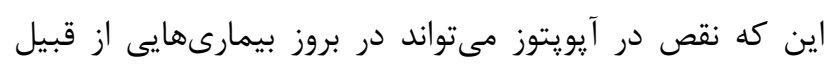

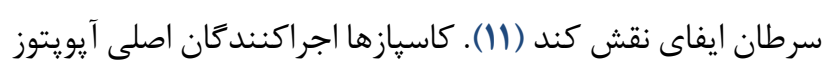

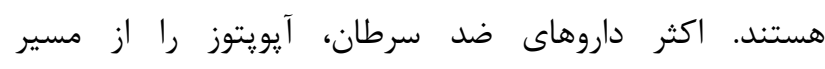

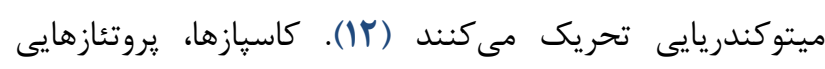

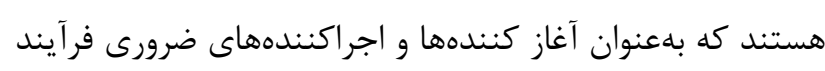
آيويتيك ايفاى نقش مى كنند. به صورت كلاسيك، آبشار كاسيازى آنه

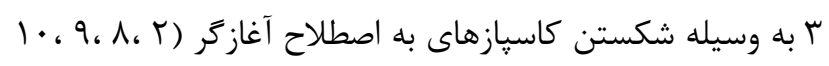

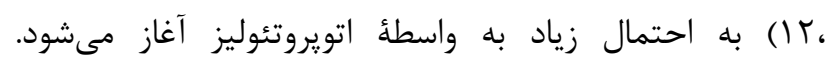

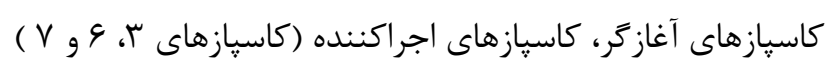

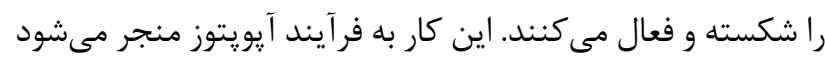

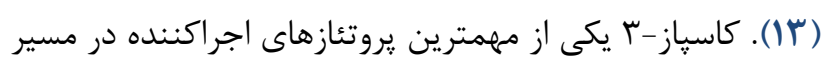

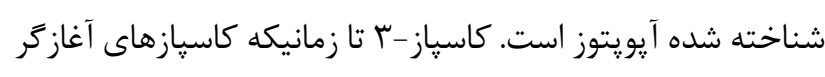

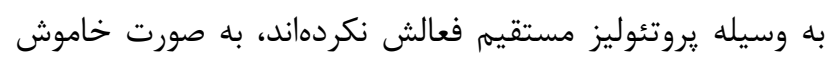


ساير قسمتها جدا مى كنند)، براى تعيين كيفيت و كميت DNA

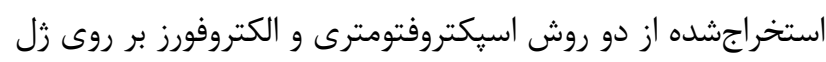

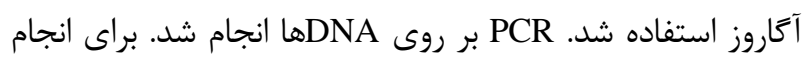

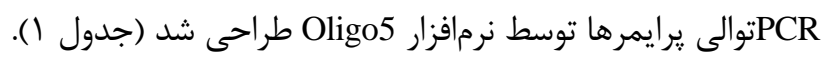

شناسايى باكترى به روش زنجيرهاى يليمراز

شناسايى باكترى در نمونههاى جمعآورى شده با استخراج

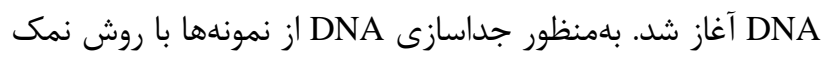

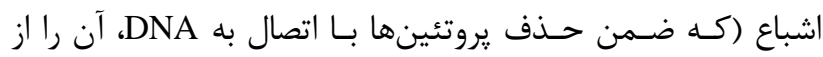

جدول ا. توالى هرايمرهاى مورد استفاده جهت شناسايى باكترى لاكتوباسيلوس برويس

\section{اندازه محصول}

$10 \cdot \mathrm{bp}$ $\left(5^{\prime}-3^{\prime}\right)$

F: GAACGCGAAGAACCTTAC

R: GCGTGTGTACAAGACCC
ز

16 s rRNA
مقدار مناسبى از باكترى لاكتوباسيل برويس زنده به جاهكها

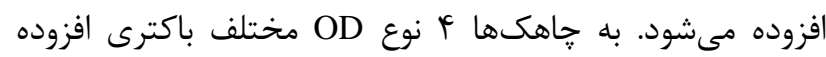
مىشود و يليتها به مدت ؟، 9 ساعت براى تأثير باكترىها انكوبه

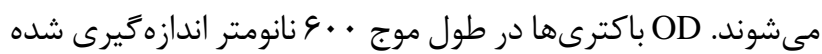

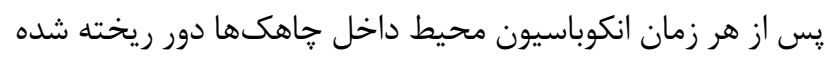

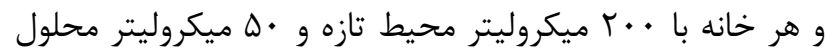
جايگزين مىشود. سلولهاى تيمار نشده با باكترى بهعنوان MTT

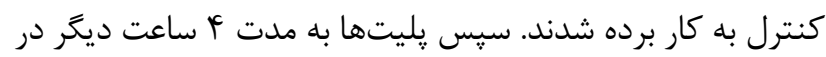

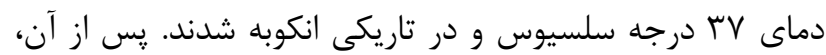
محلول MTT با · · م ميكروليتر DMSO به همراه ضr ميكروليتر

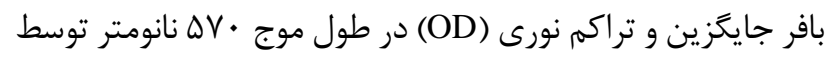

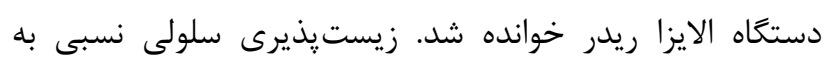

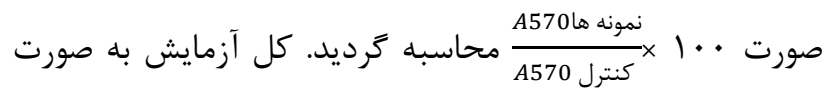
سه تكرار انجام شد (19) (1).

\section{رنََآميزى سلولى ديى (Dapi Staining)}

DAPI (4',6-diamidino-2-phenylindole) رنگآميزى روشى مناسب و سريع براى تشخيص اجسام آيويتوتيك و به تبع

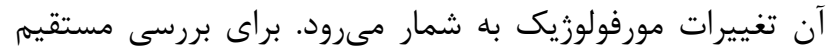

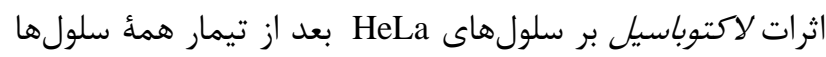

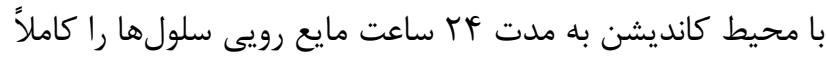

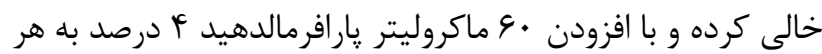

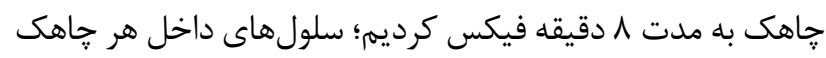

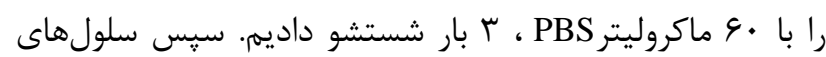
ماخل هر جاهك با • بو ماكروليتر محلول نفوذيذيركننده

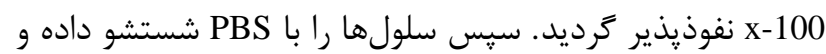

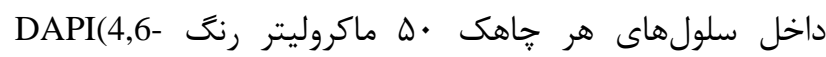
ريخته و انكوبه كرده، دوباره ץ بار diamidino- 2-phenylindole)

\section{كار با سلولهاى سرطانى HeLa}

در اين يروزه سلولهاى سرطانى HeLa از بانك سلولى انيستيتوى ياستور ايران تهيه شد. سلولها در داخل فلاسك حاوى لهرى

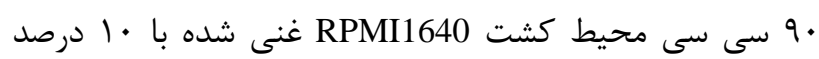

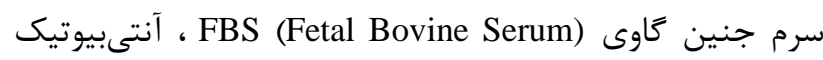
كشت (penicillin $0.1 \mu \mathrm{g} / \mu \mathrm{L}$ and streptomycin $0.1 \mu \mathrm{g} / \mu \mathrm{L}$ ) داده شد. بعد از يك شبانه روز با PBS شستشو داده و محيط

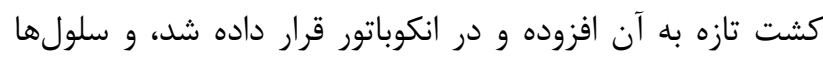

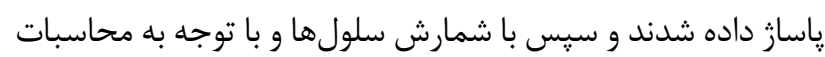
مربوط به seeding density مورد نظر براى انجام آزمايشات، مقدار مورد نياز از سوسيانسيون سلولى توسط محيط كشت كامل به به به به

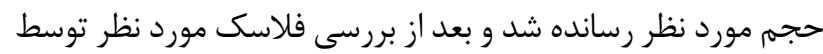

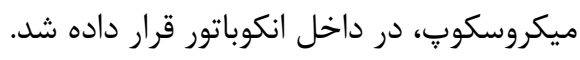

تعيين درصد زنده بودن سلولها (viability test)

در اين مرحله، سلولها با ترييان بلو رنغآميزى شد. . . ماكروليتر از محلول يكنواخت حاوى سلولها داخل تيوب ريخته و به مقدار برابر يعنى ترييان بلو افزوده شد. سيس با با استفاده از لام

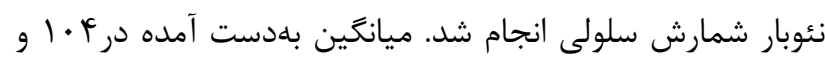

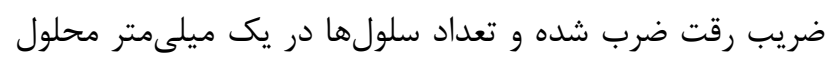
بهدست آمد.

\section{(Microculture Tetrazolium Test) MTT تست}

تست MTT روش رنگسنجى بريايه احيا شدن و شكسته

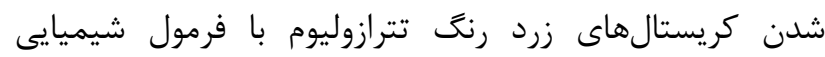
bromide 3-(4,5-Dimethylthiazol-2-yl)-2,5-diphenyltetrazolium، به وسيلة آنزيم سوكسينات دهيدروزناز و تشكيل كريستال هاى آبى

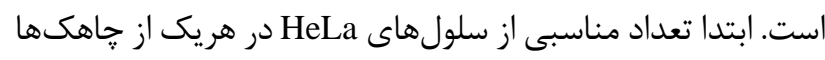

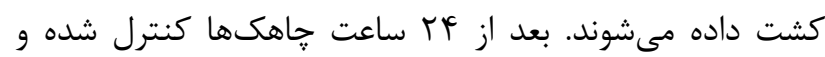




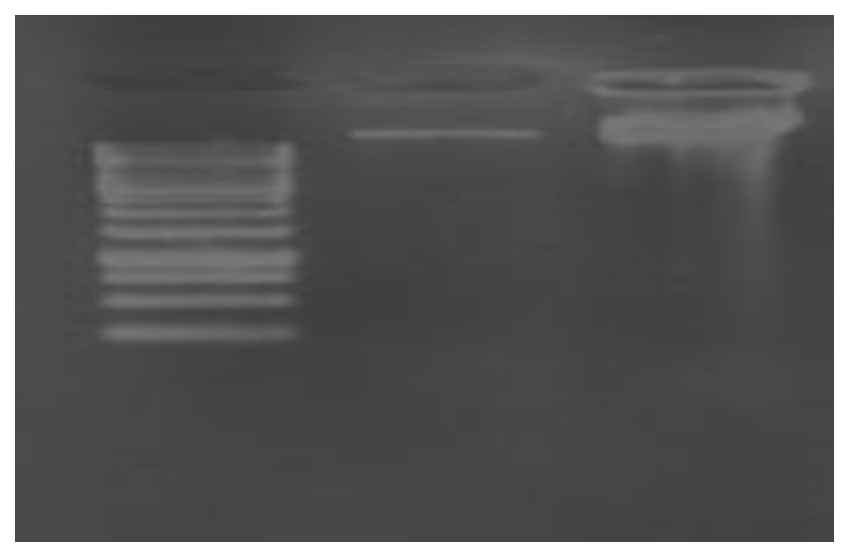

شكل I. DNA استخراج شده براى لاكتوباسيلوس برويس بر روى زل أل اكارز الدرصد

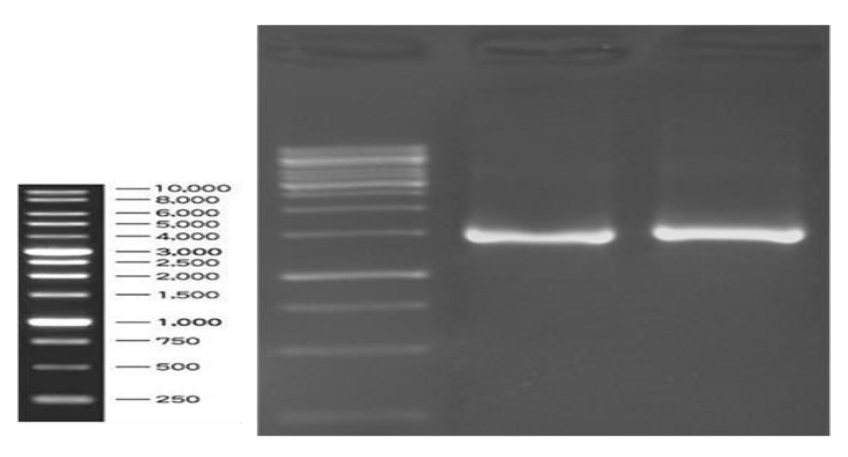

شكل ז. الكتروفورز آكارز باكترىهاى لاكتوباسيل جداسازى شده ازمايع نمونها.

\section{رنى آميزى DAPI}

نتايج رنغآميزى مAPI جهت بررسى آيويتوزهاى حاصل

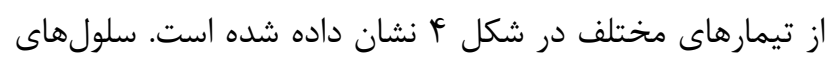

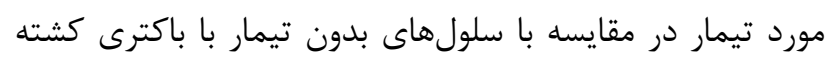
شده وارد آيويتوز شده و هستههاى ريزترى را تشكيل دادهاند.

\section{RNA استخراج}

بلمنظور ارزيابى تغييرات بيان زنها، سلولهاى HeLa تحت

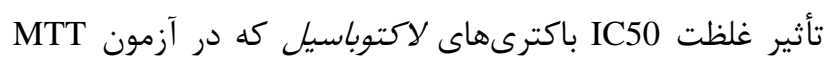
بهدست آمده بود قرار گركتند. سيس RNA اين سلولها استخراج
استخراج DNA زنومى باكترىها و الكتروفورز براى DNA

$$
\text { ى استخراجى باكترىها }
$$

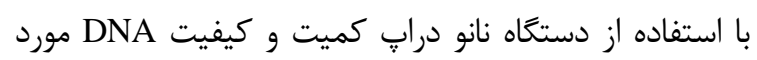

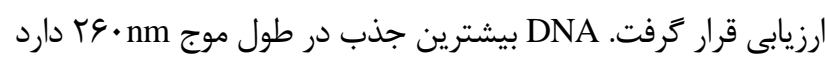

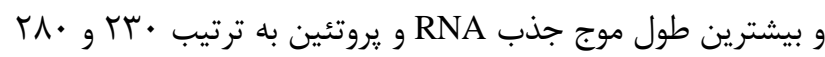

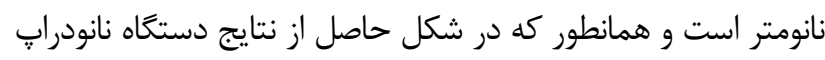

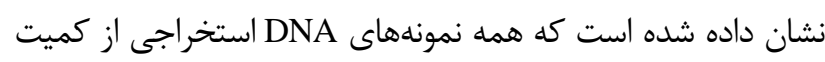

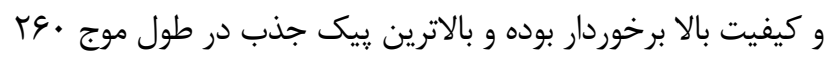

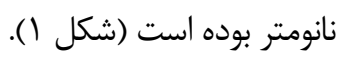

\section{S rDNA انجام واكنش زنجيرهاى يليمراز براى ثن}

همانطور كه مشاهده مىشود انتظار بر آن است كه يس از

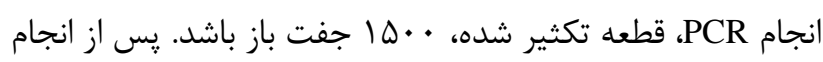

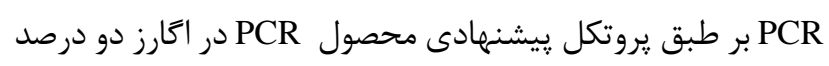

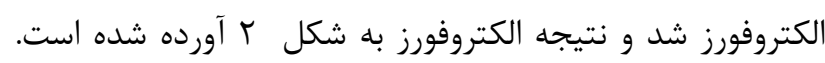

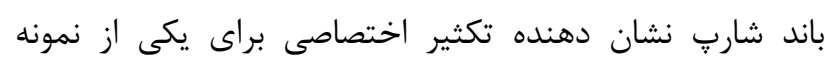
باكترى ها بوده است (شكل r).

\section{بررسى سميت باكترىهاى جداشده بر روى}

\section{سلول سرطانى HeLa}

بلمنظور بررسى سمى بودن باكترىهاى لاكتوباسيل بر روى ، بادي

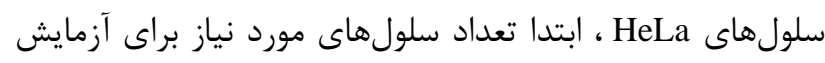

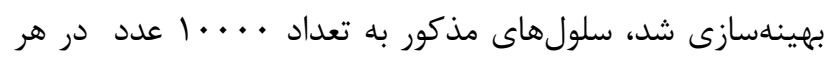

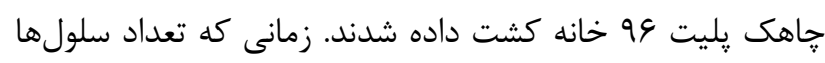

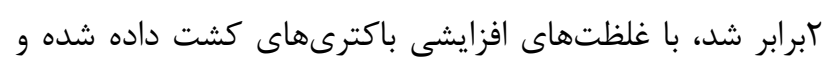

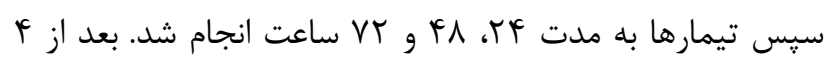

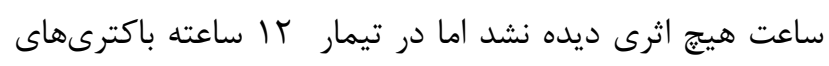

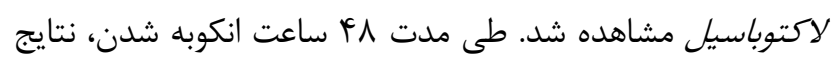

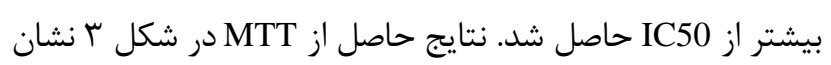

داده شدهاند. 


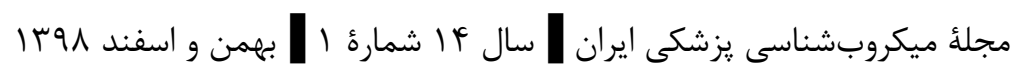

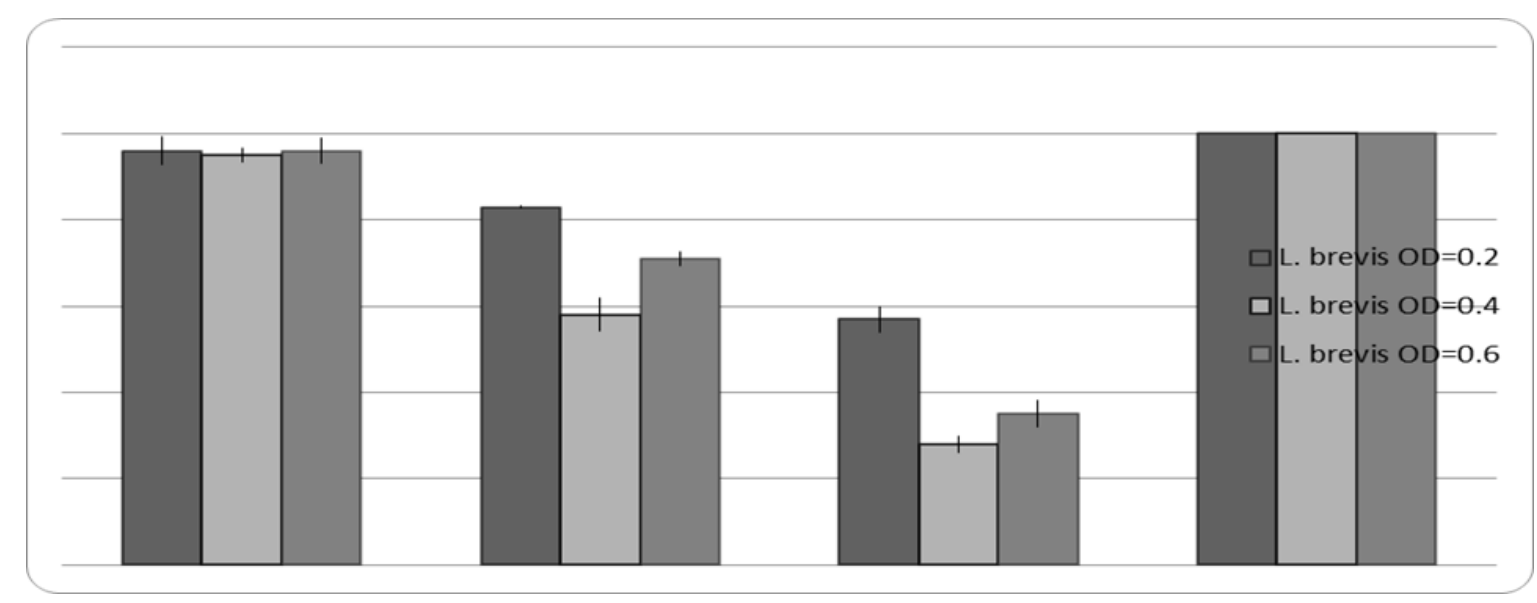

شكل r. اثر تيمارهاى زمانى مختلف بركشت لاكتوباسيلوس برويس.
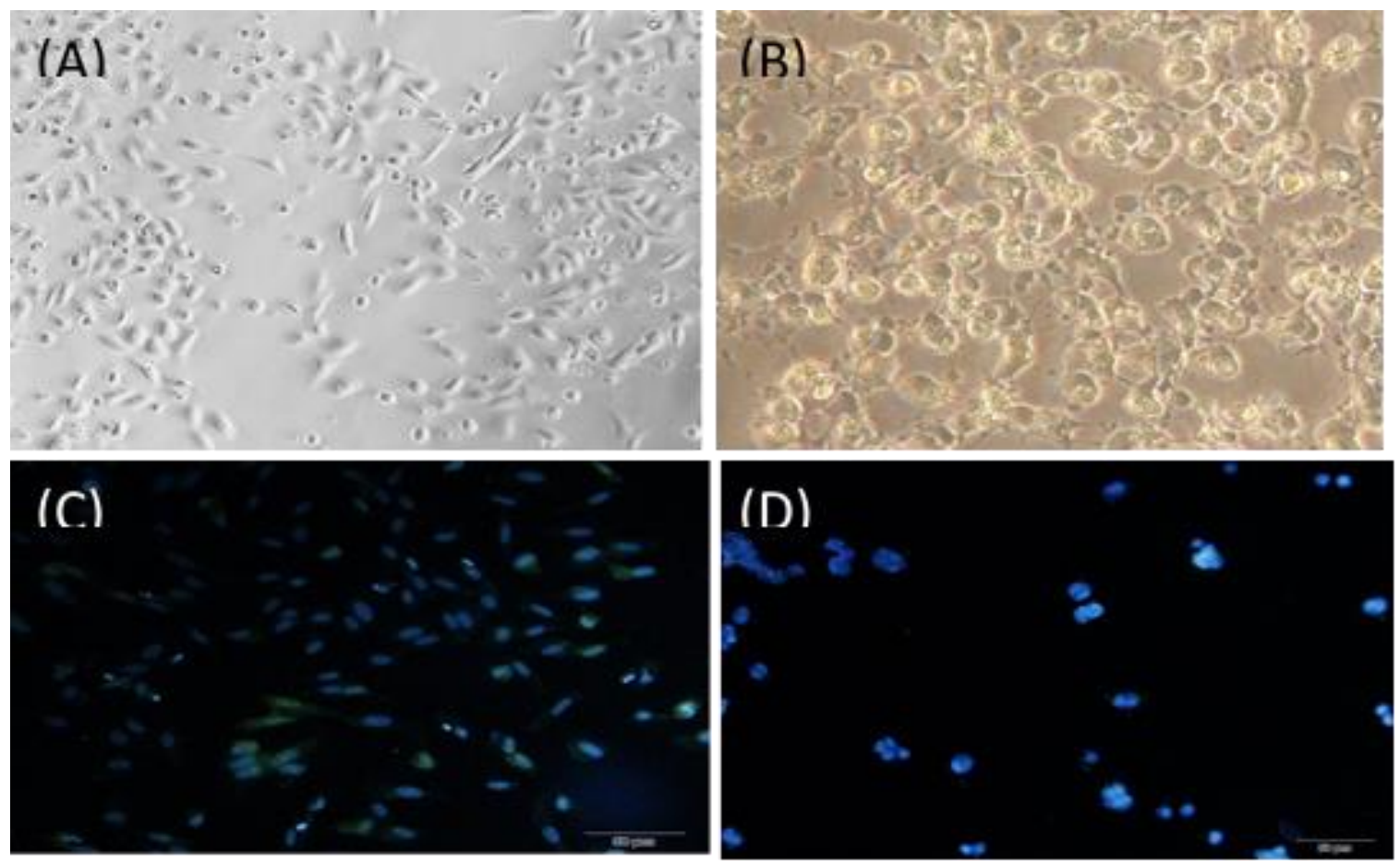

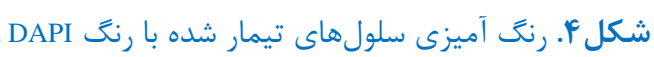

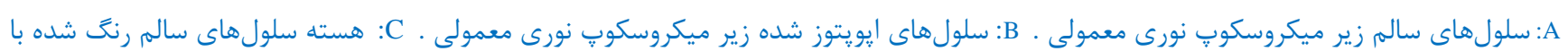

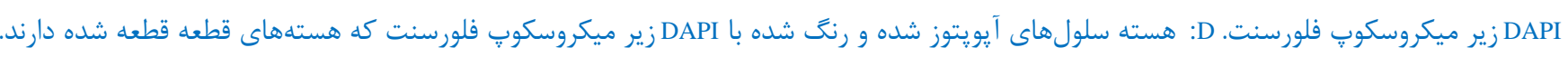

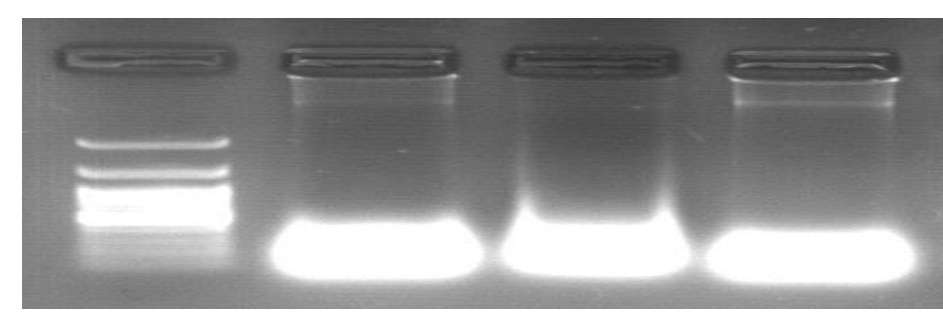

شكله. تصوير زل الكتروفورز Total RNA استخراج شده از نمونهها. 


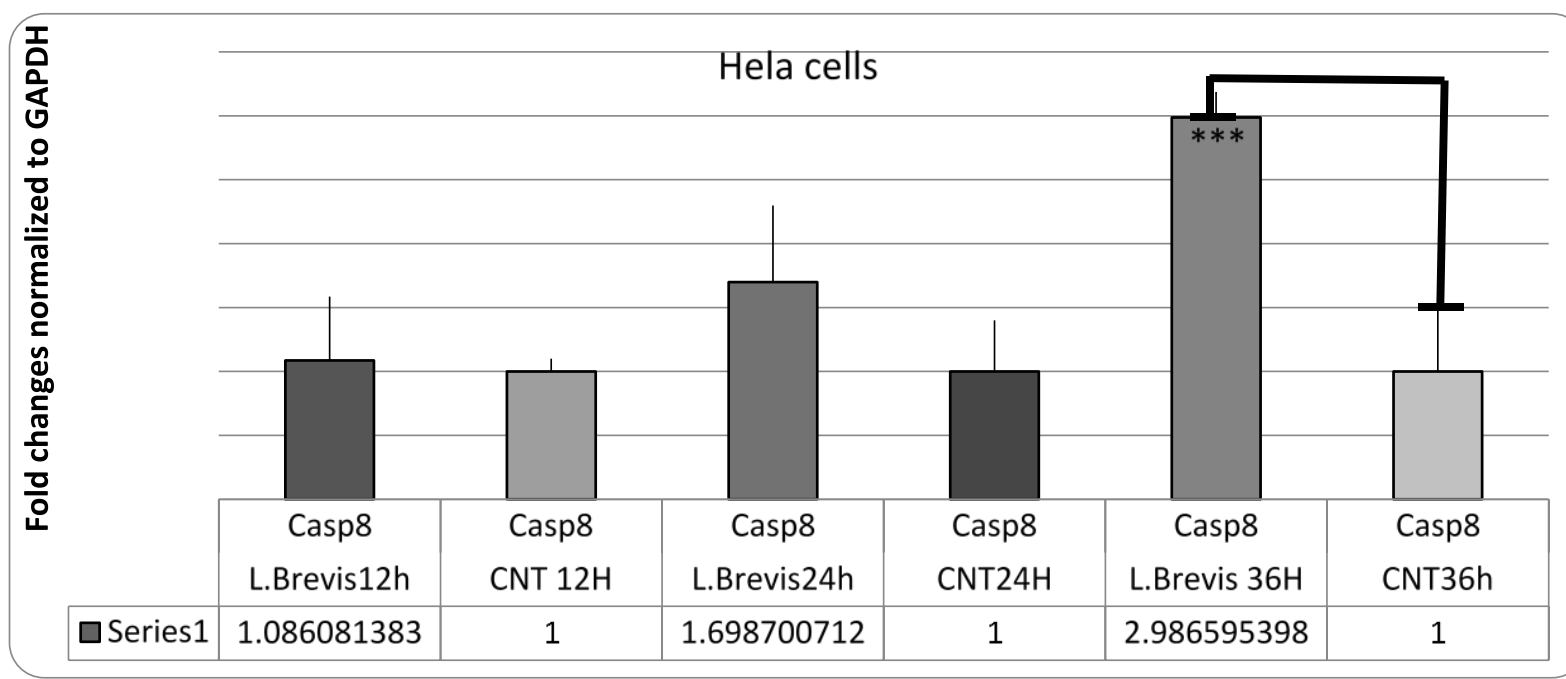

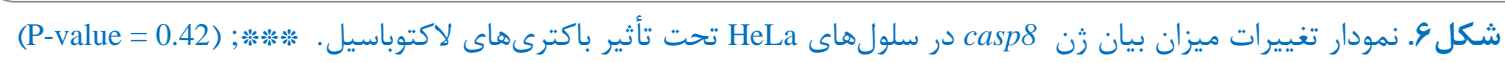

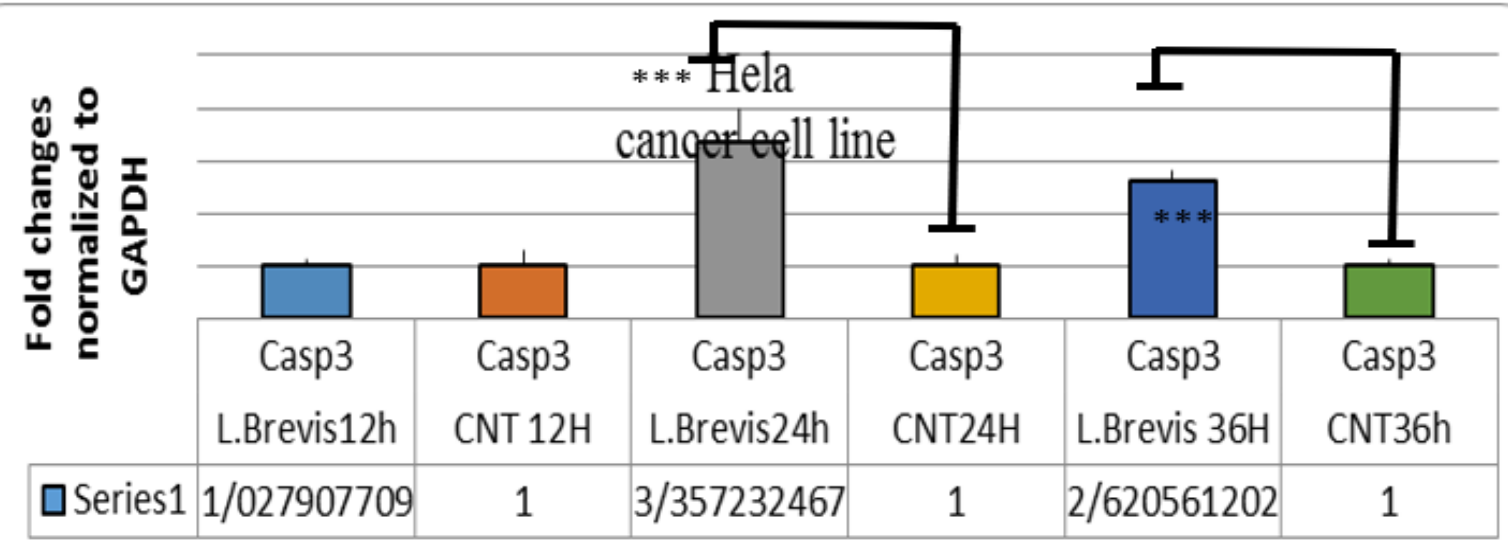

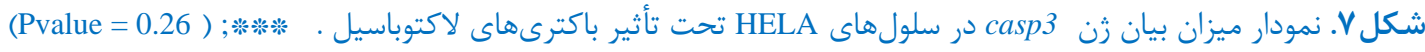

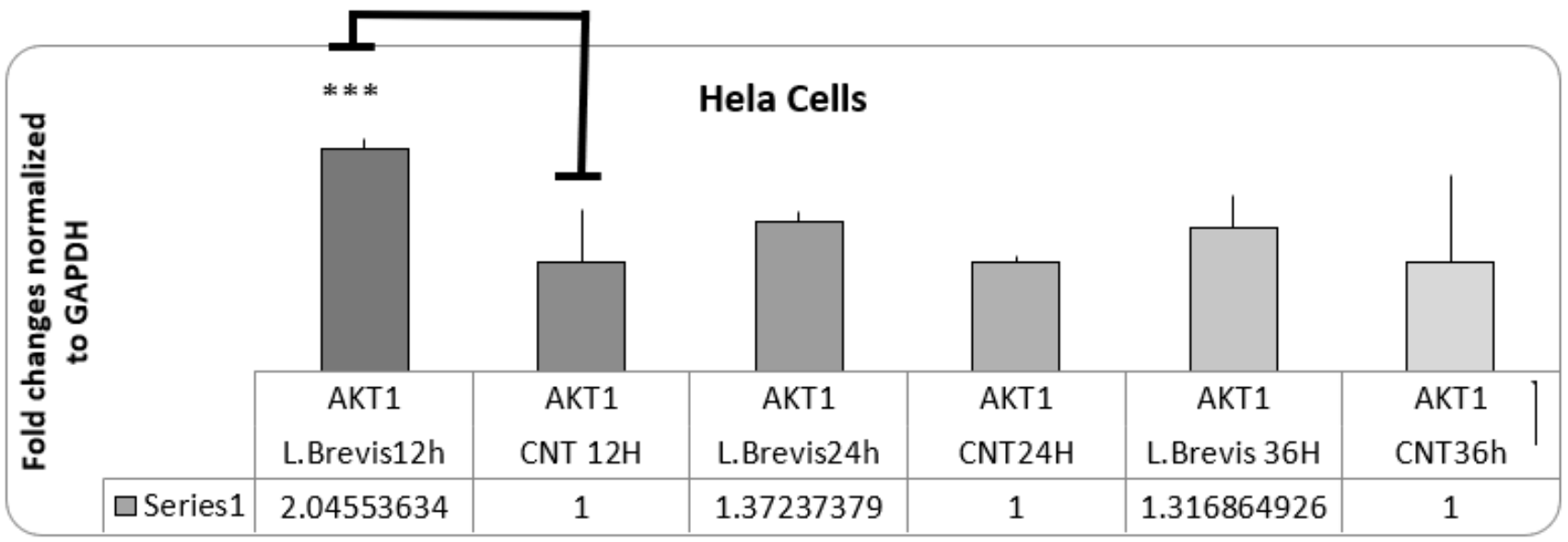

شكل ^. نمودار تغييرات ميزان بيان زن akt در سلولهاى HeLa تحت تأثير باكترىهاى لاكتوباسيل P-value = 0.42 در ساعت اوليه زن AKT1 به علت مقاومت سرطان به ايويتوز افزايش بيان داشته است. 
همجنين در يروهش هايى كه انجام شده بر خلاف تصور رايج، نشان داده شده است كه لاكتوباسيلهاى وازينال نه تنها در درئ جلوگيرى از بروز عفونتهاى باكتريايى و قارجى بلكه در كنترل و نشان ييشخيرى از عفونتهاى ويروسى و سرطان نيز مؤثر هستند. با بان توجه به اين نتايج، تقويت و حفظ فلور ميكروبى لاكتوباسيلوس فهاى

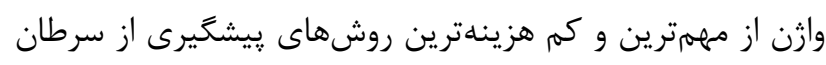

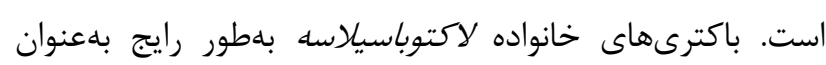
يروبيوتيك در ماست و ساير لبنيات يافت مىشوند. ويثزى هاى تنظيه كنندگى و تحريك كنندگى اين باكترىها بر سيستهم ايمنى دئى

ميزبان به خوبى در مطالعات كذشته مشخص شده است (سT) نتايج تستهاى انجام شده برروى رده سلولى HeLa و تيمارهاى

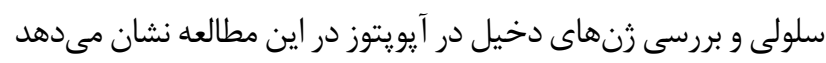

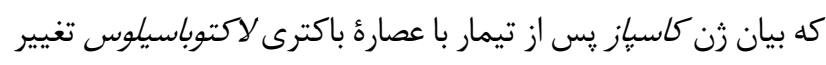

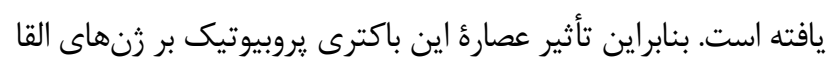

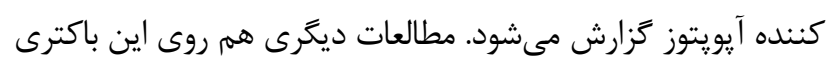
يروبيوتيك و خواص ضد سرطانى آن انجام گرفته است كه ارزش غذايى اين يروبيوتيك را به ثابت كرده است. سلولهاى سرطانى از طريق يك سرى از فرآيندهاى تنظيم

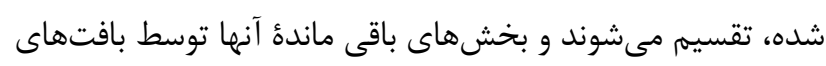
مجاور و سلولهاى ايمنى جذب مى شوند. مطالعات متعدد نشان داد كه باكترىهاى يروبيوتيك مى توانند نقش مهرى درى در تنظيم آيويتوز از طريق مسيرهاى درونى و بيرونى داشته باشند. فعال

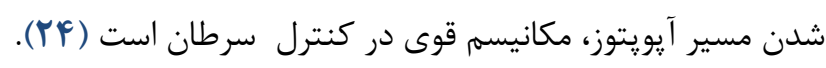
اين نتايج، با يافتههاى با مطالعه حاضر همخوانى دارد. در مطالعه Esmaeili و همكاران در سال rا •r شناسايى

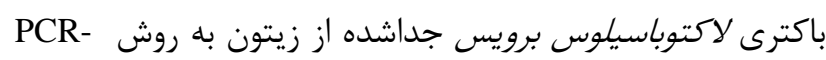
RFLP محيط MRS كشت داده شد و تستهاى بيوشيميايى انجام كرفت.

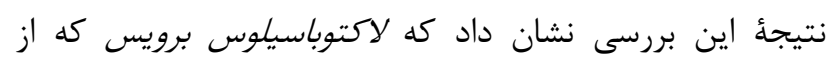
سويههاى يروبيوتيك است قابل جداسازى از زيتون ايران است.

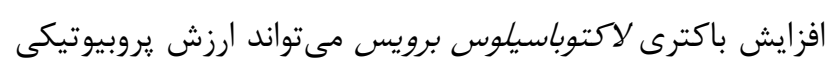

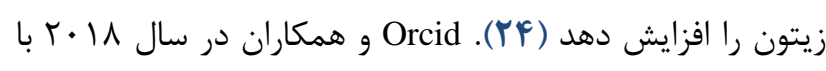
بررسى تأثير لاكتوباسيلوس برويس بر بهبود كاستريت معده ناشى دهى

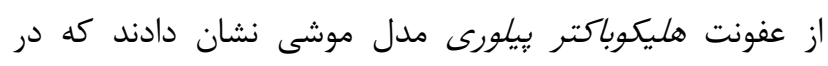

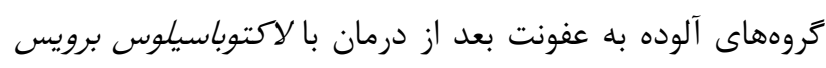

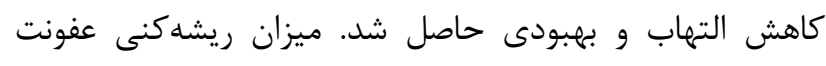

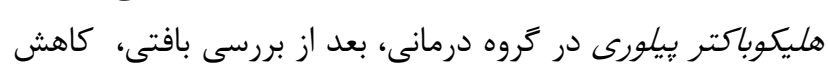

با توجه به اينكه زن atk1 نقش بسيار مهمى در بيولوزى

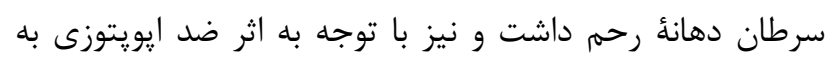
منظور اطمينان بيشتر اين زن نيز مورد بررسى قرار كرفت. همانطور

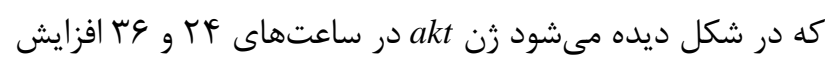
معنى دارى ندارد و به سلولها اجازه داده خواهد شد نسبت به به ديه يديده ايويتوز اقدام نمايند.

ويزگگى اصلى سلولهاى سرطانى تكثير غير قابل كنترل

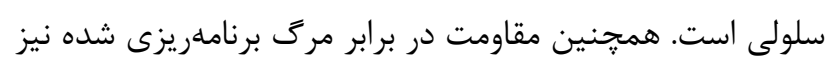

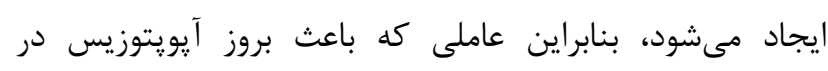

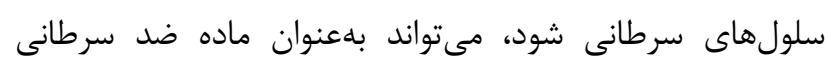

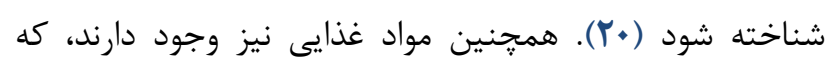
مىتوانند بر روى كنترل رشد سلولهاى سرطانى، تاثير مثبت

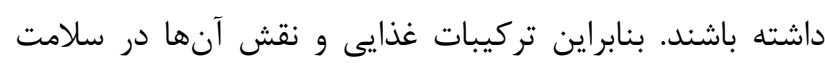

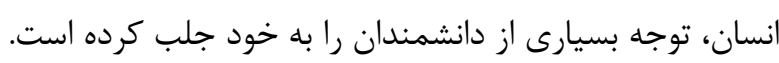
يروبيوتيكها نوعى از اركانيسههاى غير بيمارىزا در مواد

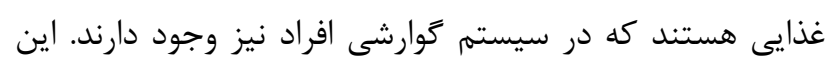
ميكروار كانيسهها نيز اثرات مفيدى بر سلامت ميزبان دارند. كزارش شده است كه يروبيوتيكهاى خاصى داراى فعاليتهاى ضدسرطانى هستند (II). نتايج تستهاى انجام شده

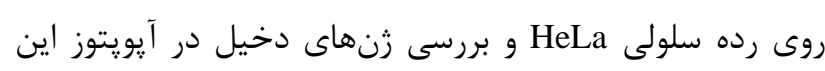

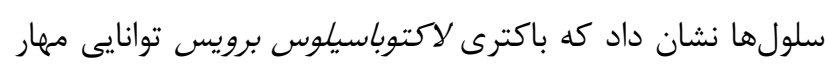

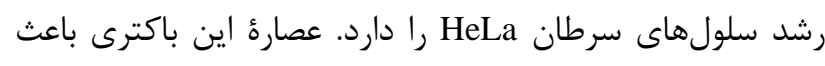

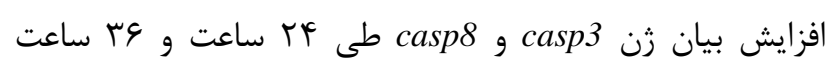

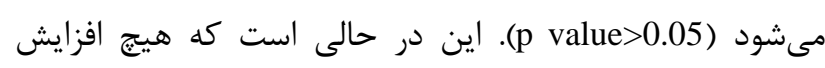

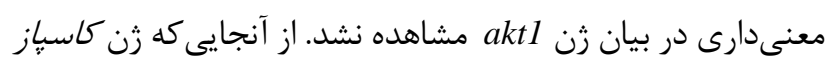

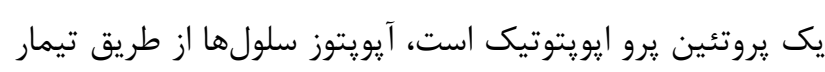

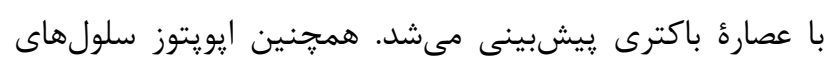

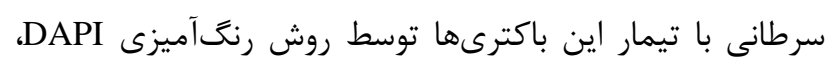

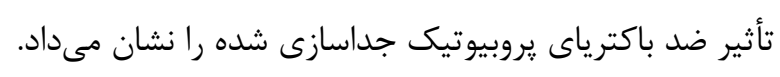
مطالعات مختلفى كه روى بروبيوتيكها انجام كرفت، نشان

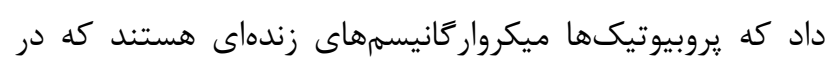

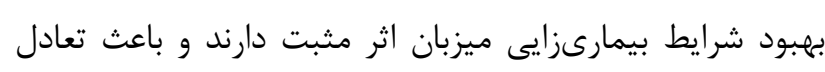

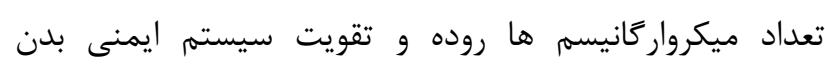

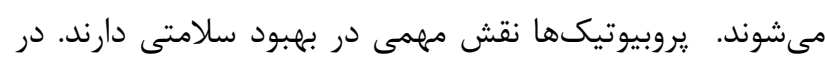

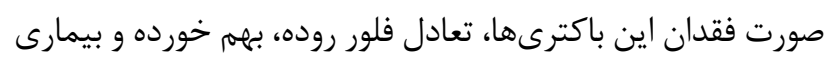

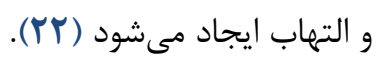


و همكاران در سال Iim در MCF7 تيمار شده، نشان مى دهد كه افزايش فعاليتهاى كاري كاسياز

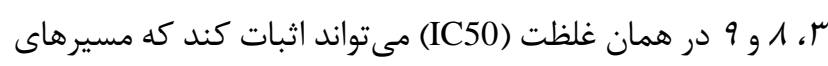

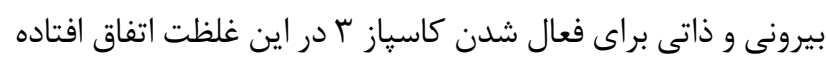

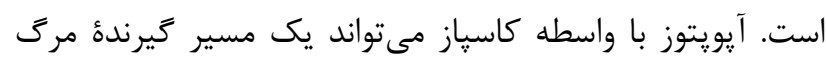

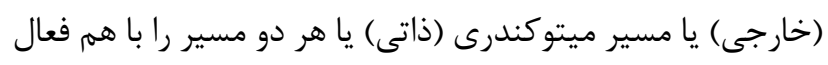

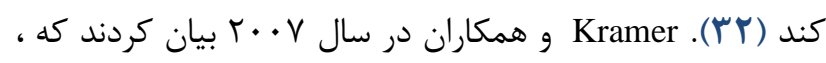
FASD به Paso-caspase-8

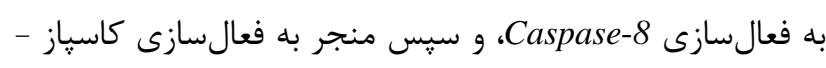

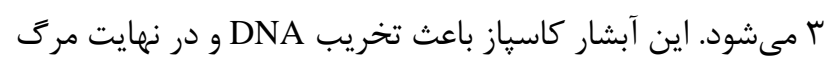

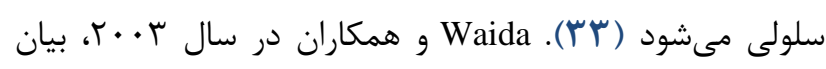

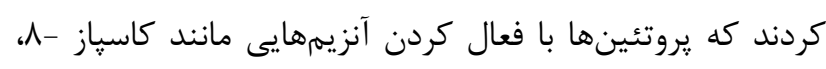

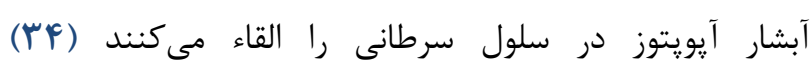
Balasubashini

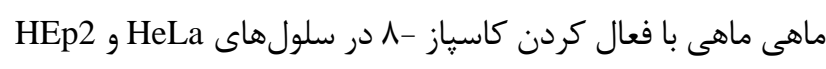

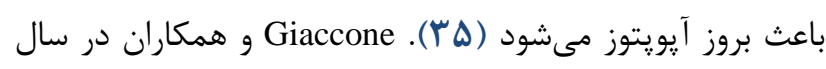

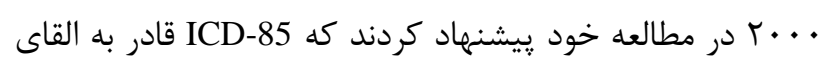

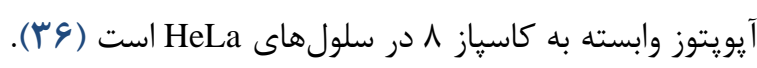

$$
\text { نتيجه كيرى }
$$

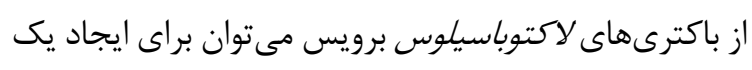

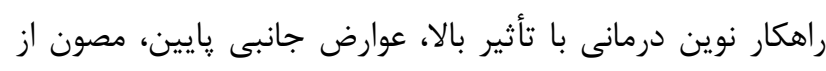

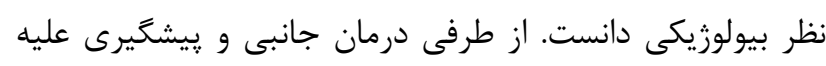
سرطان مقرون به صرفه خواهد بود.

$$
\text { سياسگزارى }
$$

بدينوسيله از معاونت آموزشى و يزوهشى دانشخاه آزاد اسلامى

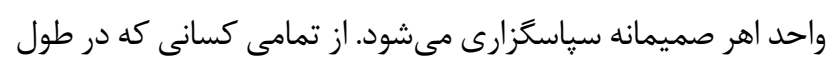

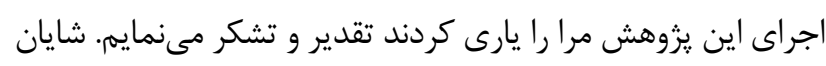

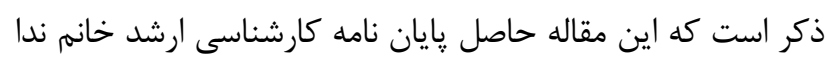

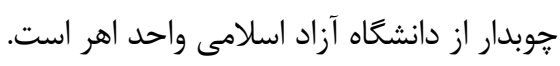

$$
\text { تعارض در منافع }
$$

در انجام مطالعة حاضر، نويسندًان هيجَّونه تضاد منافعى

نداشتهاند.

$$
\text { منابع مالى }
$$

منابع مالى اين تحقيق توسط، دانشعاه اصفهان تامين شده است.
التهاب را نشان داد. نتايج مطالعه Orcid، با مطالعئ ما همخوانى

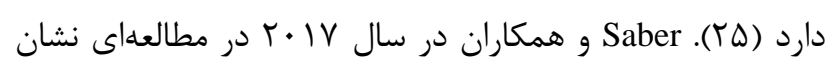

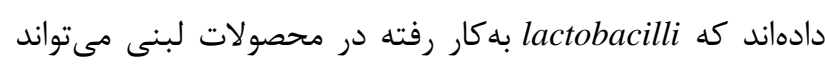
ياسخ ايمنى ميزبان را تقويت نمايد (צ؟). باتوجه به مطالعات كذشته، وجود كاسيازها و مسير سيكنالينگ akt در سلول سرطانى دهانه رحم و مرى سلو سلول

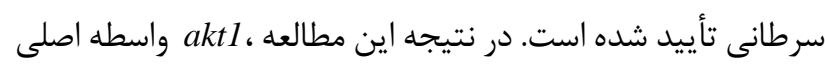

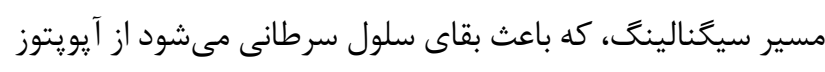

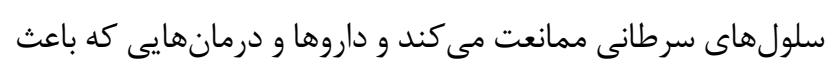

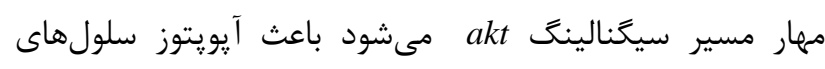

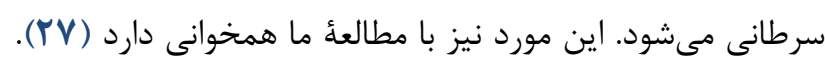

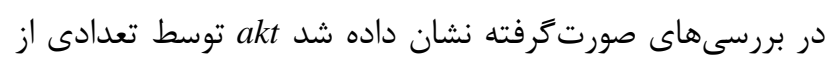

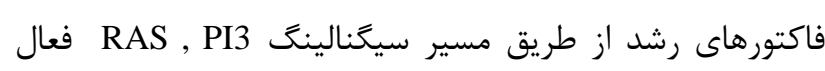

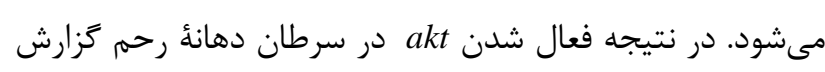

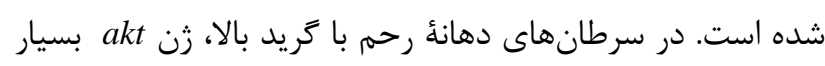

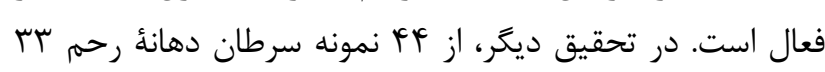

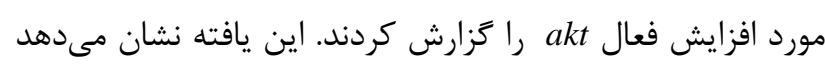

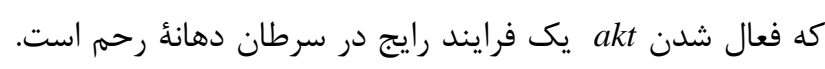
مسير akt يك هدف مهمم براى مطالعه سرطان دهانه دانه رحم است.

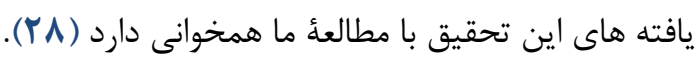

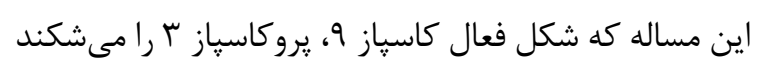

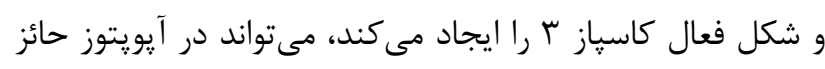

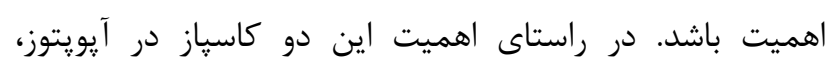

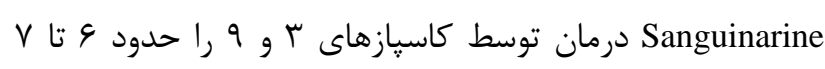

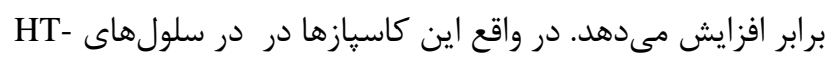

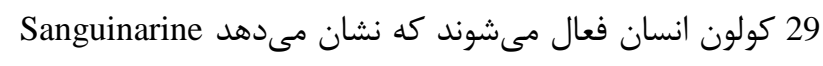

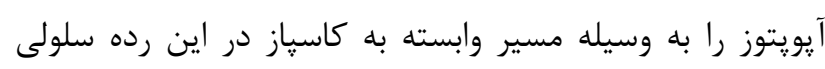

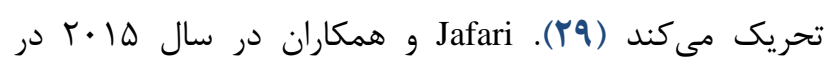

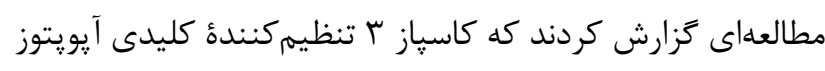

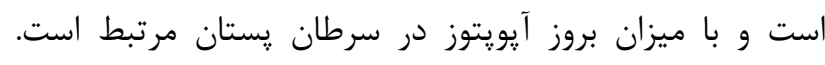

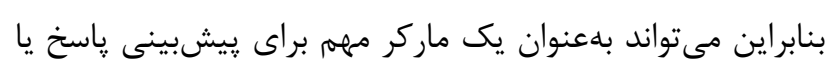

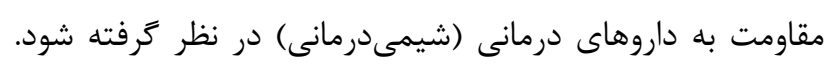

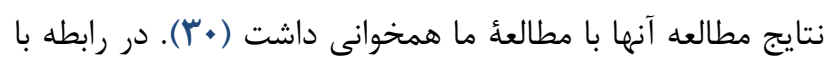

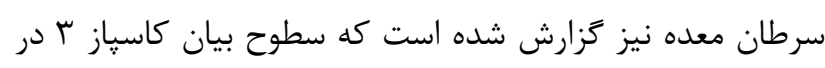

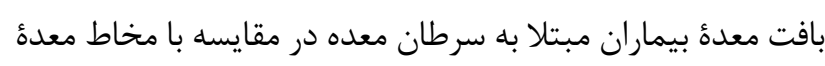

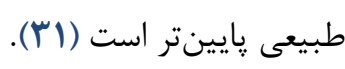


1. Hong S, Cheng S, Songock W, Bodily J, Laimins LA. Suppression of microRNA 424 level\% human papillomaviruses is necessary for differentiationdependent genome amplification. J Virol. 2017; 15;91(24):e01712-1717. [DOI:10.1128/JVI.01712-17] [PMID] [PMCID]

2. Roberts CC1, Tadesse AS, Sands J, Halvorsen T, Schofield TL, Dalen A, et al. Detection of HPV in Norwegian cervical biopsy specimens with type-specific PCR and reverse line blot assays. J Clin Virol. 2006;36(4):277-282. [DOI:10.1016/j.jcv.2006.03.013] [PMID]

3. Rahbari R, Sheahan T, Modes V, Collier P, Macfarlane C, Badge RM. A novel L1 retrotransposon marker for HeLa cell line identification. Bio Techniques. 2009; 46: 277-84. [DOI:10.2144/000113089] [PMID] [PMCID]

4. Scherer WF, Syverton JT, Gey GO. Studies on the propagation in vitro of poliomyelitis viruses. IV. Viral multiplication in a stable strain of human malignant epithelial cells (strain HeLa) derived from an epidermoid carcinoma of the cervix. J Exp Med. 1953; 97:695-710. [DOI:10.1084/jem.97.5.695] [PMID] [PMCID]

5. Moore MR1. Opposed to the being of Henrietta: Bio slavery, pop culture and the third life of HeLa cells. Med Humanit. 2017;43(1):55-61. [DOI:10.1136/medhum2016-011072] [PMID]

6. Guandalini S, Cernat E, Moscoso D. Prebiotics and probiotics in irritable bowel syndrome and inflammatory bowel disease in children. Benef Microbes. 2015; 6(2): 209-217. [DOI:10.3920/BM2014.0067] [PMID]

7. Whelan K. Probiotics and prebiotics in the management of irritable bowel syndrome: a review of recent clinical trials and systematic reviews. Current Opinion in Clinical Nutrition \& Metabolic Care. 2011 Nov 1;14(6):581-7. [DOI:10.1097/MCO.0b013e32834b8082] [PMID]

8. 8.BarronsR, Tassone D . Use of Lactobacillus probiotics for bacterial genitourinary infections in women: a review.

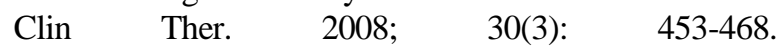
[DOI:10.1016/j.clinthera.2008.03.013] [PMID]

9. 9.Honardoost M, Soleimanjahi H, Rajaei F. Apoptosis: programmed cell death. J Qazin Univ MedSci. 2013;17(3):48-57.

10. Devarajan E, Sahin AA, Chen JS, Krishnamurthy RR, Aggarwal N, Brun AM, et al. Down-regulation of caspase 3 in breast cancer: a possible mechanism for chemo resistance. Oncogene .2002;21(57):8843-8851. [DOI:10.1038/sj.onc.1206044] [PMID]

11. Glenn K. Venoms to drugs: Translating venom peptides into therapeutics. Aust Biochem 2013;44(3):13-16.

12. Chien SY1, Wu YC, Chung JG, Yang JS, Lu HF, Tsou $\mathrm{MF}$, et al. Quercetin induced apoptosis acts through mitochondrial- and caspase-3-dependent pathways in human breast cancer MDAMB-231 cells. Hum Exp Toxicol. 2009; 28(8): 493-503. [DOI:10.1177/0960327109107002] [PMID]

13. Rodríguez-Berriguete G, Galvis L, Fraile B, de Bethencourt FR, Martínez-Onsurbe P, Olmedilla G, Paniagua R, et al. Immunoreactivity to caspase-3, caspase7 , caspase-8, and caspase- 9 forms is frequently lost in human prostate tumors. Hum Pathol 2012; 43(2): 229237. [DOI:10.1016/j.humpath.2011.04.024] [PMID]

14. Harada H, Hiraoka M, Kizaka-Kondoh S. Antitumor effect of TAT-oxygen dependent degradation-caspase-3 fusion protein specifically stabilized and activated in hypoxic tumor cells. Cancer Res 2002; 62(7): 2013-8.

15. Yang S, Zhou Q, Yang XC. Aspase-3 status is a determinant of the differential responses to genistein between MDA-MB231 and MCF-7 breast cancer cells. Biochim Biophys Acta 2007; 1773(6): 903-11. [DOI:10.1016/j.bbamcr.2007.03.021] [PMID]

16. Li Y, Liu J, Liu X, Xing K, Wang Y, Li F, Yao L. Resveratrol-induced cell inhibition of growth and apoptosis in MCF7 human breast cancer cells are associated with modulation of phosphorylated Akt and caspase-9. Appl Biochem Biotechnol. 2006; 135(3): 181192. [DOI:10.1385/ABAB:135:3:181]

17. Kim R, Emi M, Tanabe K, Murakami S, Uchida Y, Arihiro K. Regulation and interplay of apoptotic and nonapoptotic cell death. J Pathol 2006; 208: 319-326. [DOI:10.1002/path.1885] [PMID]

18. Ferchichi, M., Valcheva, R., Vost, H., Onno, B. and Dousset, X. Molecular identification of the microbiota of French sourdough using temporal temperature gradient gel electrophoresis. Food Microbiology 2007; 24: 678686. [DOI:10.1016/j.fm.2007.04.001] [PMID]

19. Javidnia K, Miri R, Amirghofran Z, Jafari A, Amoozegar Z. Cytotoxicity and antimicrobial assessment of Euphoria hebecarpa. Iran j Pharm Res 2004; 3(2): 75-82.

20. Daniluk U. Probiotics, the New Approach for Cancer Prevention and/or Potentialization of Anti-cancer Treatment. J clin Exp On.col 2012; 1: 2. [DOI:10.4172/2324-9110.1000e105]

21. de Moreno de LeBlanc A, Matar C, LeBlanc N, Perdigón G. Effects of milk fermented by Lactobacillus helveticus R389 on a murine breast cancer model. Breast Cancer Res 2005;7(4):R477-86. [DOI:10.1186/bcr1032] [PMID] [PMCID]

22. Rosenfeldt, V., Benfeldt, E., Nielsen, S.D., Michaelsen, K.F., Jeppesen, D.L., Valerius, N.H. and Paerregaard, A. Effect of probiotic Lactobacillus strains in children with atopic dermatitisJ. Allergy Clin. Immunol. 2003; 111(2),389-395. [DOI:10.1067/mai.2003.389] [PMID] 
23. Zhong, L., Zhang, X. and Covasa, M. Emerging roles of lactic acid bacteria in protection against colorectal cancer. World J Gastroenterol. 2014; 20(24),.7878. [DOI:10.3748/wjg.v20.i24.7878] [PMID] [PMCID]

24. Esmaeili T, Emami Z, Ahadi A.M, Shahanipour K, Shafigi M. Identification OF Lactobacillu Plantarum Isolated from olive by PCR-RFLP. J Microbiol biotechn. $2012 ; 12,21-28$

25. ORCID B., Kermanian, F, Khalili F, Sadat Z.R.N, Yaslianifard S. Influence of Lactobacillus brevis on the recovery of gastric gastritis caused by Helicobacter pylori infection in a C57BL / 6 mouse model. Knowledge Health. 2018;13 (2):15-21.

26. Saber A, Alipour B, Faghfoori Z, Yari Khosroushahi A. Cellular and molecular effects of yeast probiotics on cancer. Crit. Rev. Microbiol. 2017;43(1):96-115. [DOI:10.1080/1040841X.2016.1179622] [PMID]

27. Vivanco I, Sawyers CL. The phosphatidylinositol 3kinase-AKT pathway in human cancer. Nature Reviews Cancer. 2002;2(7):489. [DOI:10.1038/nrc839] [PMID]

28. Malur S, Krause N, Köhler C, Schneider A. Sentinel lymph node detection in patients with cervical cancer. Gynecologic oncology. 2001;80(2):254-7. [DOI:10.1006/gyno.2000.6041] [PMID]

29. Lee JS, Jung WK, Jeong MH, Yoon TR, Kim HK. Sanguinarine induces apoptosis of HT-29 human colon cancer cells via the regulation of $\mathrm{Bax} / \mathrm{Bcl}-2$ ratio and caspase-9-dependent pathway. Int J Toxicol 2012; 31: 707. O'Donovan N O'Donovan N1, Crown J, Stunell H, Hill $\mathrm{AD}, \mathrm{McDermott} \mathrm{E}, \mathrm{O}$ 'Higgins N, et al. Caspase 3 in breast cancer. Clin CancerRes 2003; 9: 738-42. [DOI:10.1177/1091581811423845] [PMID]

30. Jafari A,1 Hassan Pourrazi,1, Saeid Nikookheslat, and Behzad Baradaran. Effect of Exercise Training on Bcl-2 and Bax Gene Expression in the Rat Heart. Gene Cell Tissue. 2015; 1;182:258-66. [DOI:10.17795/gct-32833]

31. Kim PK, Armstrong M, Liu Y, Yan P, Bucher B, Zuckerbraun BS, et al. IRF-1 expression induces apoptosis and inhibits tumor growth in mouse mammary cancer cells in vitro and in vivo. Oncogene 2004; 23: 1125-1135. [DOI:10.1038/sj.onc.1207023] [PMID]

32. Lim, S. W., Loh, H. S., Ting, K. N., Bradshaw, T. D., and Zeenathul, N. A. (2014). Antiproliferation and induction of caspase-8-dependent mitochondria-mediated apoptosis by $\beta$-tocotrienol in human lung and brain cancer cell lines. Biomed. Pharmacother. 68, 1105-1115. [DOI:10.1016/j.biopha.2014.10.006] [PMID]

33. Kramer PH, Arnold R, Lavrik IN: Life and death in peripheral T cells. Nat Rev Immunol 2007, 7:532-542 [DOI:10.1038/nri2115] [PMID]

34. Waida JS, Dowdy SF. Modulation of cellular function by TAT mediated transduction of full-length proteins. Curr Protein PeptSci.2003; 4:97-104
35. Balasubashini M Sri, Karthigayan S, Somasundaram ST, Balasubramanian T, Rukkumani R, Venugopal PM. FV peptide induces apoptosis in HEp 2 and HeLa cells: an insight into the mechanism of induction. Journal of Carcinogenesis.2006; 5:1-9. [DOI:10.1186/1477-3163-51] [PMID] [PMCID]

36. Giaccone. Chemotherapy Triggers Apoptosis in a Caspase-8-dependent and Mitochondria controlled Manner in the Non-Small Cell Lung Cancer Cell Line NCIH460. Cancer Research. 2000; 60:7133-41. [DOI:10.2174/1389203033487289] [PMID] 